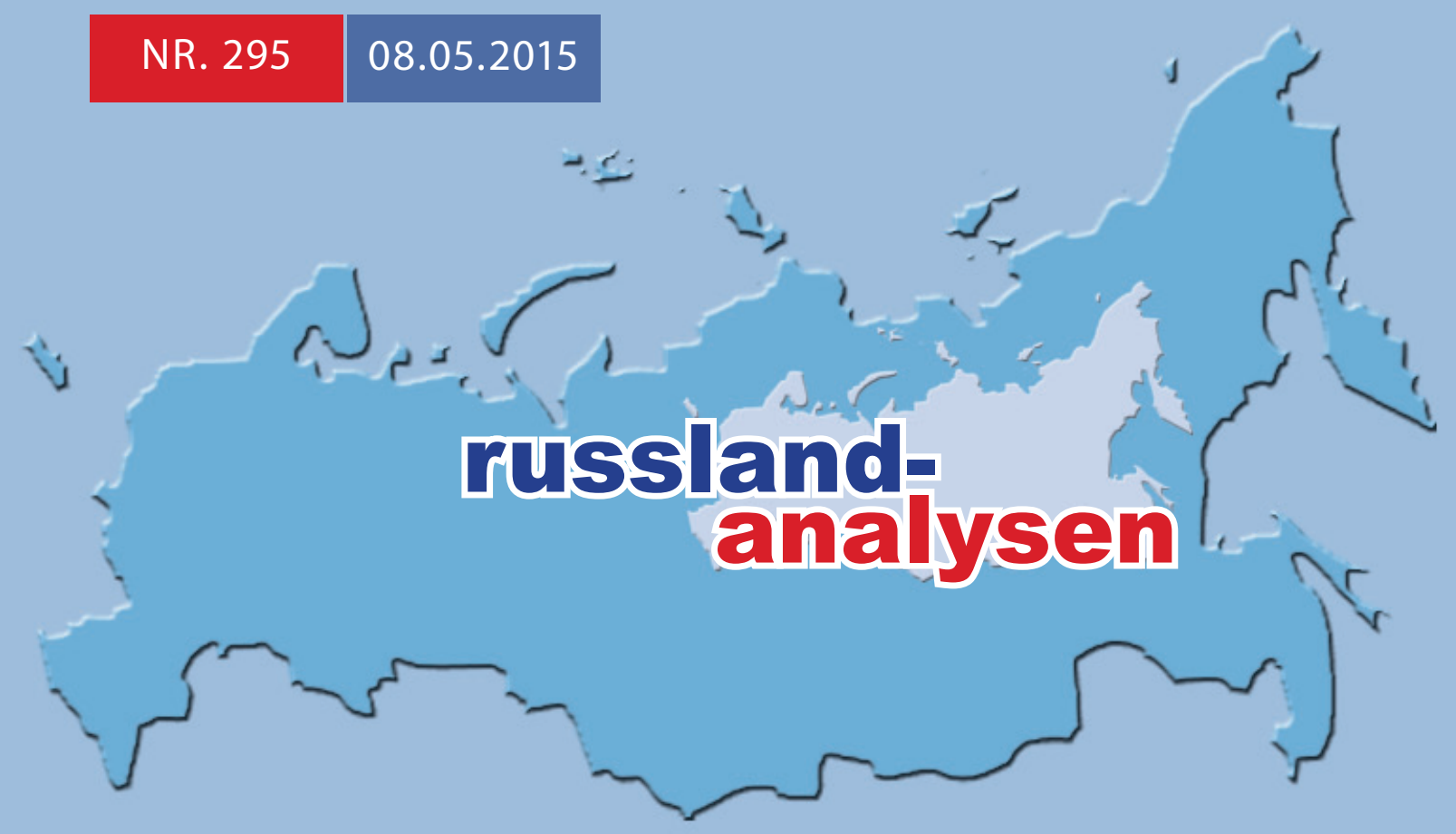

http://www.laender-analysen.de/russland/

\title{
DIE RUSSLAND-UKRAINE-KRISE
}

aNALYSE

Ist die Krim wirklich russisch?

Russische Juristen diskutieren über die Rechtmäßigkeit der Aufnahme der Krim

Caroline von Gall, Köln

ANALYSE

Der Ukraine-Krieg und die europäische Sicherheitsarchitektur

Ulrich Kühn, Hamburg

- KOMMENTAR

Leitgedanken für die nun notwendige Russlandpolitik

Zusammenarbeit, soweit wie möglich. Gefahrenabwehr, soweit wie nötig

Karsten D. Voigt, Berlin

UMFRAGE

Die Russland-Ukraine-Krise in russischen Umfragen $\quad 13$

Russlands internationale Rolle

Russlands Weg

70 Jahre Sieg im »Großen Vaterländischen Krieg«

AUS RUSSISCHEN BLOGS

Sexismus-Debatte

NOTIZEN AUS MOSKAU

Über Gedöns

Jens Siegert, Moskau

CHRONIK

23. April - 7. Mai 2015 


\section{Ist die Krim wirklich russisch?}

\section{Russische Juristen diskutieren über die Rechtmäßigkeit der Aufnahme der Krim}

Caroline von Gall, Köln

\section{Zusammenfassung}

Am 19. März 2014 hatte das russische Verfassungsgericht den Vertrag über den Anschluss der Krim geprüft und für verfassungsgemäß erklärt. Dieses Urteil hat nun die Verfassungsrechtlerin Lukjanowa in der »Nowaja Gaseta« einer scharfen Kritik unterzogen. Darauf antwortete niemand Geringeres als Verfassungsgerichtspräsident Walerij Sorkin in der Regierungszeitung »Rossijskaja Gaseta». In einer heftigen Replik warnte er vor einer Schwächung des Staates durch Kritik. Angesichts der allgemeinen Gefahr für das Recht, sei eine juristische Debatte über Verfassungsverstöße bei Maßnahmen gegen größeres Unrecht selbstzerstörerisch.

Tatsächlich vertreten die rechtswissenschaftlichen Eliten in der Mehrheit die Argumentation der staatlichen Propaganda und kreieren so zusätzliche Legitimation für die Politik. Auch das Urteil des Verfassungsgerichts zur Krim-Frage dient dazu, die staatliche Politik zusätzlich zu legitimieren. Der Streit zwischen Lukjanowa und Sorkin zeigt aber auch, dass die Rechtswissenschaft in Russland keineswegs ein homogener Monolith ist.

\section{Ein juristischer Schlagabtausch}

Es war eine kleine Sensation, als die Verfassungsrechtlerin Jelena Lukjanowa, Professorin an der Rechtswissenschaftlichen Fakultät der Moskauer Higher School of Economics, am 19. März 2015 in der liberalen Zeitung »Nowaja Gaseta" in einem langen Artikel (<http:// www.novayagazeta.ru/politics/67715.html >) die Rechtmäßigkeit des Beitritts der Krim zur Russischen Föderation verneinte. Mit sehr deutlichen Worten erklärte sie unter Bezugnahme auf die populäre Losung der PutinAnhänger »die Krim ist unser» (»Krim nasch»), warum die Krim nach den russischen Gesetzen "nicht so ganz unser» (»ne sowsem nasch») sei.

Ausgangspunkt ihrer Analyse war die russische Verfassung, konkreter Anlass das Urteil des russischen Verfassungsgerichts vom 19. März 2014, in dem der Vertrag über den Anschluss der Krim geprüft und für verfassungsgemäß erklärt wurde. Sollte die Autorin angenommen haben, dass die Nowaja Gaseta nur von einem kleinen Kreis Oppositioneller gelesen würde, die ihre Meinung teilten, so hatte sie sich geirrt. Denn wenige Tage später erschien eine Replik des in Lukjanowas Artikel direkt angegriffenen russischen Verfassungsgerichtspräsidenten Walerij Sorkin in der Regierungszeitung "Rossijskaja Gaseta«. Liberale Juristen und Oppositionelle, die von Sorkin seit langem als Speerspitze gegen die Macht verachtet werden, zeigten sich tief beeindruckt von Lukjanowa.

Bis zu diesem Schlagabtausch hatte die Annexion der Krim in der russischen Rechtswissenschaft kaum intensive fachliche Debatten entfacht. Vielmehr hatten sich die führenden Völkerrechtler Russlands mit Kritik auffallend zurückgehalten. Im Juni 2014 meldeten sie sich jedoch mit einem auch auf Englisch verfassten kol- lektiven Appell zu Wort, der vom Präsidenten der Russischen Vereinigung für Völkerrecht, Anatolij Kapustin, unterzeichnet wurde (<http://www.ilarb.ru/html/ news/2014/5062014.pdf $>$ ). Der Aufruf war nach einer gemeinsam mit der russischen Diplomatenakademie veranstalteten Konferenz entstanden und zeugt von der engen Verflechtung der führenden Völkerrechtler mit der russischen Diplomatie. Der Aufruf verfolgt mehrere Argumentationsstränge, die nicht immer juristisch sind, dafür aber mit der offiziellen staatlichen russischen Linie übereinstimmen.

Zum einen wird historisch argumentiert: Die Krim sei »über Jahrhunderte" russisch und der Wechsel der Krim zur Ukraine 1954 nicht rechtsgültig gewesen. Also sei die Krim 1991 durch die Ukraine annektiert worden.

Zum anderen beschreibt das Dokument die ukrainische Regierung als ein durch einen verfassungswidrigen blutigen Putsch an die Macht gelangtes faschistisches Unrechtsregime. Dieses unterdrücke insbesondere durch die Sprachengesetzgebung die "russische« Bevölkerung in der Ukraine und spalte Russen und Ukrainer. Der verfassungswidrige Putsch und die antirussische Politik der Kiewer Regierung berechtige das Volk der Krim aufgrund seines Selbstbestimmungsrechts zum Referendum und zur Unabhängigkeitserklärung. Als Präzedenzfall wird der Kosovo herangezogen, wo die Loslösung von Serbien sogar ohne Referendum vollzogen wurde. Als zweiter Präzedenzfall dient das Plebiszit in Nord-Schleswig aus dem Jahr 1920 über die Vereinigung mit Dänemark. Dieses zweite Beispiel wurde offensichtlich gewählt, da Russland zunächst eigentlich selbst die Loslösung des Kosovo von Serbien als völkerrechtswidrig zurückgewiesen hatte. Allerdings ist die Argumentation durchaus inkonsistent, denn wäre die 
Krim tatsächlich aufgrund einer rechtswidrigen Schenkung nie Teil der Ukraine gewesen, käme es nicht mehr auf das Selbstbestimmungsrecht an.

Ungewöhnlich scharf wird in dem Dokument der Westen angegriffen: Die USA und Europa würden die Politik des unrechtmäßigen »Kiewer Regimes« unterstützen. Der Vorwurf, Russland habe das Referendum auf der Krim durch militärischen Druck beeinflusst und unterstütze die Separatisten in der Ostukraine, wird als Lüge des Westens zurückgewiesen.

Die Rechtfertigung mit Bezug auf das Selbstbestimmungsrecht entspricht der Linie Putins. Der hatte die Annexion der Krim in seiner Rede an die Föderalversammlung vom 18. März 2014 mit dem Selbstbestimmungsrecht der Völker begründet. Er argumentierte, die Rechte der Menschen auf der Krim und in Sewastopol seien nach dem gewaltsamen Putsch in Kiew gefährdet gewesen, daher hätten sie sich an Russland gewandt. Putin verglich die Situation auf der Krim mit der seinerzeitigen im Kosovo. So zitiert er das Kosovo-Gutachten des Internationalen Gerichtshofs, der 2010 erklärt hatte, dass einseitige Unabhängigkeitserklärungen völkerrechtlich nicht verboten seien.

Völkerrechtliche Verträge, in denen sich Russland verpflichtet, die territoriale Integrität der Ukraine zu achten, etwa das Budapester Memorandum (1994) und das Schwarzmeerflottenstatut (1997), verschweigt Putin ebenso wie den Einsatz russischer Streitkräfte auf der Krim, der zusätzlich einen Verstoß gegen das Gewaltverbot der Vereinten Nationen darstellt.

Zwar gibt es immer wieder junge Juristen, die insbesondere im Internet das Vorgehen Russlands in der Ukraine aus völkerrechtlicher Perspektive kritisch beurteilen, etablierte Juristen hatten sich jedoch mit Kritik weitgehend zurück gehalten.

\section{Lukjanowas Kritik an der russischen Justiz}

Während also die führenden Völkerrechtler Russlands kollektiv die russische Politik in der Krim-Frage rechtfertigen, wagt Jelena Lukjanowa nun einen Frontalangriff. Ihr Ziel ist nicht der Präsident Russlands, sondern das Urteil des Verfassungsgerichts vom 19. März 2014, in dem der Vertrag über den Anschluss der Krim geprüft und für verfassungsgemäß erklärt wurde. Geprüft wurden dabei sowohl der Beitrittsvertrag zwischen der Krim und der Russischen Föderation als auch das russische Gesetz über die Aufnahme der Krim.

Der Aufsatz beschränkt sich aber nicht auf juristische Fragen. Vielmehr führt die Autorin einen regelrechten Rundumschlag. Der Kritik am Urteil stellt sie eine allgemeine, sehr deutliche Kritik an der Justiz und den russischen Juristen voran. Lukjanowa kritisiert, dass Begriffe aus der für Russland verbindlichen Europäi- schen Menschenrechtskonvention in Russland nicht verstanden werden. Auch der aus der westlichen Lehre übernommene Rechtsstaatsbegriff der russischen Verfassung ("prawowoje gosudarstwo») werde nicht im eigentlichen Sinn begriffen. Lukjanowa fragt sich, wie in Russland überhaupt eine entsprechende Rechtsstaatsdogmatik entstehen kann, wenn der Staat in den Lehrbücher noch immer als "Form der Organisation der Gesellschaft» und damit als der Gesellschaft gegenüber dominant definiert wird.

Anhand von zahlreichen Beispielen kritisiert sie die Strukturen in der Justiz, die die Richter in eine Abhängigkeit von der Politik bringen. Die guten Juristen in Russland seien von der staatlichen Rechtsprechung ausgeschlossen. In den letzten zwanzig Jahren seien nur bequeme Rechtsvollstrecker in diese Ämter gewählt worden. Im Ergebnis gebe es in Russland heute zwei Gruppen von Juristen: Auf der einen Seite »Justizbeamte, Richter, Parlamentarier sowie Mitglieder der Wahlkommissionen und Mitarbeiter der Strafverfolgungsbehörden«, auf der anderen Seite Rechtsanwälte, Menschenrechtsverteidiger und zum Teil auch unabhängige Wissenschaftler.

\section{Die Entscheidung des Verfassungsgerichts zur Krim}

Wenn sich Lukjanowa im zweiten Teil des Aufsatzes dem Urteil des Verfassungsgerichts zur Krim zuwendet, suggeriert sie durch ihre Vorrede, dass der von ihr beschriebene Zustand der Justiz auch für das Verfassungsgericht gilt. Auch hier sieht sie Richter als willige Rechtsvollstrecker, die im Sinne der Politik handeln.

Im Urteil zur Krim macht Lukjanowa acht Rechtsverletzungen aus. Schon die Prüfung des Verfassungsgerichts, ob das Ratifikationsgesetz zum Beitrittsvertrag mit der Krim sowie das Gesetz über die Aufnahme der Krim in Form von zwei neuen Subjekten der Russischen Föderation (die Stadt Sewastopol und die Republik Krim) gegen die Verfassung verstoßen, sei nicht zulässig gewesen. Nach dem Verfassungsgerichtsgesetz prüft das Verfassungsgericht völkerrechtliche Verträge der Russischen Föderation nur auf Antrag eines Staatsorgans, das "Zweifel an der Verfassungsmäßigkeit des Vertrages" hat. In diesem Fall wurde die Verfassungsmäßigkeit auf Antrag von Präsident Putin geprüft. Dass dieser Zweifel an der Verfassungsmäßigkeit des Beitritts der Krim gehabt hat, sei nicht bekannt. Allerdings muss der Präsident nach Art. 7 Abs. 4 des Gesetzes über die Aufnahme neuer Subjekte dem Verfassungsgericht Aufnahmeverträge zwingend vorlegen. Hier gebe es also eine deutliche Normenkollision, die vom Gesetzgeber bisher nicht in Einklang gebracht worden sei. Für das Verfassungsgericht sei dies kein Problem gewesen. Es sei auf 
dieses Problem nicht eingegangen, sondern habe einseitig Gründe für die Annahme der Entscheidung dargelegt. Lukjanowa sieht darin einen Beleg, dass das Verfassungsgericht die Entscheidung annehmen wollte, und es daher entgegenstehende Argumente ignoriert habe.

Des Weiteren kritisiert sie, dass vorgeschriebene Verfahrensschritte für das Urteil, etwa die Einholung eines vorläufigen Erstgutachtens, nicht eingehalten wurden, obwohl das Gericht die Möglichkeit gehabt hätte, das Verfahren unter Beachtung aller vom Gesetz vorgegebenen Schritte durchzuführen und das Urteil erst später zu verkünden. Dann wäre allerdings der Vertrag noch nicht in Kraft getreten. Das Gericht begründete das verkürzte Verfahren mehrdeutig mit den "Besonderheiten des Falls."

Die Hauptkritik betrifft aber zweifelsohne die Weigerung des Verfassungsgerichts, zu prüfen, ob der Vertrag gegen das Völkerecht verstößt. Nach Art. 15 Abs. 4 der russischen Verfassung sind die allgemein anerkannten Prinzipien und Normen des Völkerrechts sowie die völkerrechtlichen Verträge Russlands Bestandteil der innerstaatlichen russischen Rechtsordnung. Sie genießen Vorrang vor einfachen russischen Gesetzen. Sie haben also auch Vorrang vor dem Ratifikations- und dem Beitrittsgesetz. Das Verfassungsgericht prüft dies nicht. Rechtfertigend berief es sich auf seine Verpflichtung, nur über Rechtsfragen entscheiden zu dürfen, nicht aber über die politische Zweckmäßigkeit eines internationalen Vertrages.

Weiter argumentiert Lukjanowa, dass die Vertreter der Krim, die den Vertrag unterzeichnet haben, nicht legitimiert gewesen seien, da sie nicht nach den geltenden ukrainischen Gesetzen in ihre Ämter gelangt waren, sondern durch die Unruhen im Zusammenhang mit der Unabhängigkeitserklärung.

Problematisch sei Lukjanowa zufolge überdies, dass der Vertrag bereits vor seiner Ratifizierung vorläufig in Kraft getreten war. Das Verfassungsgericht hatte diese Herangehensweise unter Verweis auf das Völkerrecht gebilligt. Allerdings besagt Art. 65 Abs. 2 der russischen Verfassung, dass ein neues Subjekt nach dem durch das Föderale Verfassungsgesetz festgelegten Verfahren in die Russische Föderation aufgenommen wird. Dieses wiederum bestimmt, dass ein entsprechender Vertrag nicht in Kraft treten kann, wenn das russische Verfassungsgericht erklärt, dass der Vertrag verfassungswidrig sei. Daraus leitet Lukjanowa ab, dass ein entsprechender Vertrag nach russischem Recht erst nach der Prüfung durch das Verfassungsgericht in Kraft treten könne.

Aus Lukjanowas Sicht verstößt die Entscheidung auch gegen das Vorjudikat des Verfassungsgerichts zum militärischen Einsatz in Tschetschenien. Damals hatte das Verfassungsgericht den Schutz der territorialen Inte- grität als eine der Grundlagen der Verfassungsordnung anerkannt und insofern keinen Raum für die Loslösung eines Subjekts aus dem Staatsverband gesehen. Nach Lukjanowa müsse dies auch für die Ukraine gelten.

Die achte und letzte Rechtsverletzung sieht Lukjanowa darin, dass auch die Stadt Sewastopol Teil des Vertrages und der Aufnahme geworden ist, obwohl die Stadt nicht Teil der autonomen Republik der Krim gewesen war. Sie wurde vielmehr am 19. November 1990 durch ein bilaterales Abkommen zwischen der Ukraine und Russland zu ukrainischem Territorium. Insofern wäre zu fragen gewesen, ob hier die gleichen Regeln gelten wie für die Krim. Auch darauf sei das Verfassungsgericht nicht eingegangen.

Für Lukjanowa ist die Entscheidung über die Krim insofern »ein klassisches Beispiel für die Verletzung von rule of law durch eine Fehlinterpretation von Begriffen und die Manipulation von Verfahren«. Dies macht sie dem Verfassungsgerichtspräsidenten Sorkin persönlich zum Vorwurf. Er habe Russland mit diesem Verhalten an den Rand des Abgrunds geführt. Sie nennt das »Barbarei $«$.

\section{Bewertung der Argumentation von Lukjanowa}

Man muss Lukjanowa nicht in jedem Punkt folgen. Vor allem ist fraglich, ob die Tschetschenien-Entscheidung richtigerweise als Präzedenzfall herangezogen werden kann. Der Schutz der territorialen Integrität durch die russische Verfassung kann nicht einfach auf andere Staaten übertragen werden. Doch hat sie in der Mehrzahl der anderen Punkte recht: So setzte sich das Verfassungsgericht über die Gesetzesforderung hinweg, dass der Antragsteller Zweifel an der Verfassungsmäßigkeit der Gesetze haben muss. Dies kann nur bedeuten, dass das Gericht durch dieses die Politik bestätigende Urteil zusätzliche Legitimation für das politische Handeln erzeugen wollte. Gerichtliche Entscheidungen sollen offensichtlich dazu dienen, die Argumentation der Politik zu belegen.

Auch die schnelle Entscheidung des Verfassungsgerichts kritisiert Lukjanowa zu recht. Am zwingendsten aber ist ihr Einwand, das Verfassungsgericht habe die Gesetze am Maßstab des Völkerrechts prüfen müssen. Im Mittelpunkt der Krim-Entscheidung stand die Frage, ob der Staatspräsident nach der russischen Verfassung die Befugnis hatte, den Vertrag und das Gesetz zu unterzeichnen. Dabei überging das Verfassungsgericht deutlich Art. 15 Abs. 2 der russischen Verfassung. Danach sind die Organe der Staatsgewalt, und damit auch der Staatspräsident, an die Verfassung und die Gesetze gebunden. Nach der russischen Verfassung sind auch allgemein anerkannte Prinzipien und Nor- 
men des Völkerrechts und die völkerrechtlichen Verträge Bestandteil des russischen Rechtssystems. Die verfassungsmäßige Unterzeichnung hätte also vorausgesetzt, dass die Gesetze über die Krim dem Völkerrecht entsprechen. Hier ist insbesondere relevant, dass Russland die gegenwärtigen Grenzen der Ukraine völkerrechtlich anerkannt hatte.

Die Verletzung des Gewaltverbots hätte einer Anerkennung der Krim als unabhängigem Staat entgegengestanden. Außerdem verlief das Referendum über die Unabhängigkeit auf der Krim nicht frei, fair und friedlich, wie vom Völkerrecht gefordert. Letztlich sind keine Menschenrechtsverletzungen durch den ukrainischen Staat dokumentierbar, die den Einsatz der Streitkräfte rechtfertigen würden. Damit wäre die Aufnahme der Krim nicht nur völkerrechtswidrig, sondern auch verfassungswidrig. Dazu hat das Verfassungsgericht geschwiegen.

\section{Die Antwort von \\ Verfassungsgerichtspräsident Sorkin}

Die Antwort des Verfassungsgerichtspräsidenten in der Regierungszeitung Rossijskaja Gaseta unter dem Titel "Das Recht - und nur das Recht« (Nr. 6631, 24.03.2015; <http://www.rg.ru/2015/03/23/zorkin-site.html>) fügt sich in eine Reihe von rechtspolitischen Essays, die er dort seit Jahren in loser Folge veröffentlicht. Sie geben einen guten Einblick in die Gedankenwelt des Mannes an der Spitze des Verfassungsgerichts und erklären oder ergänzen die Urteile des Verfassungsgerichts. So warnt Sorkin regelmäßig vor Chaos und Untergang. Abschreckende Beispiele sind für ihn die Instabilität und wirtschaftliche Not der 1990er Jahre in Russland. Entsprechend wichtig sei der Schutz des Staates, des Garanten für Stabilität. Der starke Staat ist für ihn Voraussetzung für Stabilität und Wohlergehen, er verhindert den bellum omnium contra omnes. Insofern warnt er wiederholt auch die Opposition, den Staat als die Voraussetzung für Freiheit nicht zu schwächen. In diesem Sinne lehnt er auch die farbigen Revolutionen in den postsowjetischen Staaten ab. Auf Kritik am Verfassungsgericht reagiert Sorkin zum Teil sehr persönlich und pathetisch. Für Aufsehen hatte beispielsweise bereits seine Auseinandersetzungen mit der ehemaligen Verfassungsrichterin Tamara Morschtschakowa gesorgt.

Die Antwort an Lukjanowa überrascht gleichwohl aufgrund des besonders scharfen Tones, den Sorkin hier anschlägt. Seine Argumentation ist deutlich konservativer und antiwestlicher als früher. Der gesamte Text ist stark alarmistisch gehalten. Für Sorkin geht es in der Diskussion um nichts weniger als "das Schicksal Russlands«. Er schreibe »keinen politischen, sondern [...] einen philosophischen, ja sogar existenzialistischen
Aufsatz«. Sein Einwand, er schreibe als "Bürger Russlands« soll die Ausnahmesituation noch unterstreichen. Die Zeit, sich mit Fachdiskussionen unter Juristen aufzuhalten, sei, so Sorkin, vorbei.

Der Artikel konfrontiert den Leser mit einer Reihe an Lukjanowa gerichteter Fragen, die Sorkin direkt oder indirekt selbst beantwortet. Der erste Komplex beschäftigt sich mit der Frage, was die Gesellschaft zusammenhält. Über die Jahrhunderte sei Russland durch ein geistiges Band (duchownyje skrepy) zusammengehalten worden. Der von Sorkin hier verwendete russische Begriff ist ein alter Begriff, der für einen Rechtswissenschaftler ungewöhnlich ist. Er beschreibt die geistigen Grundlagen, oder, einfacher gesagt, den sozialen Kitt, der die Menschen verbindet. Der Begriff war erstmals von Präsident Putin in dessen Ansprache an die Föderalversammlung 2012 in die politische Debatte eingebracht worden. Auch Putin hatte beklagt, dass der Gesellschaft die geistige Bindung fehle. Konkret ging es Putin damals um Barmherzigkeit und Mitgefühl.

Heute verbinde das Recht die Gesellschaft, anstelle von Ideologie oder Orthodoxie, so Sorkin. Das mache das Recht so besonders wichtig. Ohne das Recht bliebe im postideologischen Zeitalter lediglich "das unendliche Chaos, der Abgrund der Asozialität«. Diese Feststellung verbindet er mit einem Vorwurf an die, wie er schreibt "sogenannte aufgeklärte Schicht der Gesellschaft", zu der er auch Lukjanowa rechnet. Ausgangspunkt ist für Sorkin erneut der Verfassungsbruch Jelzins 1993, mit dem dieser die neue russische Verfassung auf den Weg gebracht hatte. Nachdem keine Einigung über die Rolle von Präsident und Parlament in der neuen russischen Verfassung greifbar war, hatte Jelzin am 21. September 1993 das Dekret Nr. 1400 unterschrieben, mit dem die Verfassungsreform diktiert, das Parlament aufgelöst und Neuwahlen angesetzt wurden. Schon am nächsten Tag erklärte das Verfassungsgericht unter dem bereits damals amtierenden Verfassungsgerichtspräsidenten Sorkin das Dekret für verfassungswidrig. Darauf löste Präsident Jelzin im Oktober 1993 das Verfassungsgericht ebenfalls per Dekret auf. Jelzin warf dem Gericht vor, das Land durch die Einmischung in den politischen Kampf an den Rand eines Bürgerkrieges gebracht zu haben. Erst zwei Jahre später entstand es neu. Beobachter sehen in dieser Erfahrung Sorkins eine Erklärung für die seither auffallende Zurückhaltung des Gerichts, politische Fragen juristisch zu entscheiden. Auch in dem aktuellen Beitrag beschreibt Sorkin das Dekret Nr. 1400 noch einmal als tiefgreifend rechtswidrig. Daraus macht er nicht nur Jelzin, sondern der nach seiner Auffassung mit dem "geliebten charismatischen Präsidenten" solidarischen "aufgeklärten Schicht« einen Vorwurf. Er beschuldigt sie, durch ihre Solidarität mit Jelzin Russland 1993 verraten 
und in die Krise gestürzt zu haben, indem sie Demokratie und Gerechtigkeit über das Gesetz gestellt habe. Die Folge seien die problematische Privatisierung, große soziale Härten und blutige Konflikte gewesen. All dies führt er auf das rechtswidrige Dekret Nr. 1400 zurück.

Daraus zieht Sorkin eine Parallele zum Majdan. Ausführlich beschreibt er die angebliche Rechtswidrigkeit des Regierungswechsels und die Gewalt in der Ukraine. Die neue Regierung sei von der ukrainischen Verfassung nicht gedeckt. Wie die gesamte aufgeklärte Schicht Russlands verschließe auch Lukjanowa vor diesen ukrainischen Rechtsverletzungen die Augen.

Noch deutlichere Kritik richtet er an den Westen, der die Rechtsverletzungen in der Ukraine provoziert habe, wie auch damals den Rechtsbruch Jelzins. Er sieht den Majdan als vom Westen unterstützten verfassungswidrigen gewaltsamen Putsch. Russland habe daher zum Schutz der Bürger auf der Krim gehandelt. Sorkin beruft sich hier auf das im Völkerrecht neue Instrument der Schutzverantwortung, der sogenannten responsibility to protect, die die Vereinten Nationen berechtigt, zum Schutz der Menschenrechte einzugreifen, wenn ein Staat seine Bürger nicht schützen kann.

Insofern habe das Verfassungsgericht im Geiste der Verfassung entschieden, als es den ukrainischen Rechtsbruch bestrafte. Kritik am Verfassungsgericht zeugt für Sorkin nicht nur von einer falschen Rechtsauffassung, sondern von geopolitischer Naivität. Darüber hinaus attestiert er Lukjanowa »eine negative Haltung gegenüber der Macht«. Mit dieser Haltung werde sie indes Teil eines geopolitischen Spiels, in dem es darum gehe, Russland zu schwächen. Ihre Rechtsauffassung eine sie mit ihren westlichen Verbündeten und ziele darauf, Russland zu zerstören. Er macht sie quasi zur Volksfeindin.

Sorkin schließt mit einer Warnung. Er erlebe gegenwärtig eine Invasion durch westliche Fehlinformationen, durch postmoderne westliche Propaganda, die er mit den »barbarischen Invasionen" des Deutschen Ordens oder der Armee Napoleons nach Russland gleichsetzt. Dagegen gelte es, das Recht zu schützen.

\section{Bewertung}

In seinem Essay setzt sich Sorkin deutlich intensiver mit dem Völkerrecht auseinander als das Verfassungsgericht in der Krim-Entscheidung. Doch auch er wiederholt hier die einschlägigen Rechtfertigungen der russischen Politik und Diplomatie. Auf die vorgeworfenen Verfassungsverstöße geht er nicht ein. Insgesamt argumentieren Lukjanowa und Sorkin auf völlig unterschiedlichen Ebenen. Während Lukjanowa in ihrem Hauptteil rein juristisch argumentiert, bleibt Sorkin weitgehend pathetisch-politisch. Während Lukjanowa detailreich und stringent Verstöße des russischen Verfassungsrechts nachzuweisen sucht, macht Sorkin den Verfassungsbruch im Zusammenhang mit dem Kiewer Regierungswechsel zum zentralen Ereignis. Weil dieser Rechtsbruch zu Chaos und Zerstörung führe, sei das Recht insgesamt in Gefahr. Angesichts der allgemeinen Gefahr für das Recht, sei eine juristische Debatte über Verfassungsverstöße bei Maßnahmen gegen das größere Unrecht selbstzerstörerisch. Seine Argumentation hinsichtlich des Regimewechsels in Kiew bleibt jedoch pauschal. Mit Gegenargumenten setzt er sich nicht auseinander.

Auch wenn sein Einwand hinsichtlich des verfassungswidrigen Handelns von Jelzin richtig bleibt, sind seine Folgerungen daraus krude. Bedrohlich klingt seine Warnung vor dem Westen und der aufgeklärten Schicht in Russland, die er zu einer Art Fünfter Kolonne, zu ausländischen Agenten, zu Unterstützern des Westens erklärt. Sie werden zu Feinden Russlands, zur Gefahr für die Stabilität des russischen Staates und mithin zur Gefahr für das Recht. Dass Oppositionelle von diesem Verfassungsgericht keinen Schutz erwarten können, wird überdeutlich. Der Gerichtspräsident will vielmehr den Staat vor den Oppositionellen schützen. Lukjanowas juristisch argumentiertem Vorwurf, die Verfassungsbrüche des Verfassungsgerichts führten Russland in die Barbarei, setzt Sorkin die barbarische Invasion aus dem Ausland entgegen, die sein Verfassungsgericht aufhalten will, in dem es den Staat stärkt. Da nur das Recht den Staat zusammenhalten kann, dürfe Recht den Staat nicht schwächen.

\section{Fazit}

Sorkins Ausführungen entsprechen in der rechtlichen Bewertung dem erwähnten Appell der Völkerrechtler. Beide Dokumente geben den offiziellen russischen Standpunkt wieder. Während es durchaus zahlreiche jüngere russische Juristen gibt, die zum Beispiel im Internet offen Kritik an der offiziellen russischen Rechtsauffassung zur Krim-Frage äußern, bleiben die juristischen Eliten traditionell auf Seiten der Macht. Lukjanowa als profilierteste Kritikerin ist da bisher eine Ausnahme. Insgesamt aber vertreten die rechtswissenschaftlichen Eliten die Argumentation der staatlichen Propaganda und generieren so zusätzliche Legitimation für die Politik. Auch das Urteil des Verfassungsgerichts soll offensichtlich dazu dienen, der staatlichen Politik mit einem bestätigenden Urteil zusätzliche Legitimität zu verschaffen. Der Schlagabtausch zwischen Lukjanowa und Sorkin zeigt aber auch, dass die russische Rechtswissenschaft kein homogener Monolith ist. Wenn der Kreis der Juristen, die offen Kritik an der Rechtmäßigkeit der russischen Außenpolitik üben, auch klein ist, und sich die führenden Vertreter des Fachs schützend vor die Politik stellen, ohne dass eine tiefgehende juristische Debatte 
geführt würde, so zeigt Lukjanowa, dass es neben den staatsloyalen Juristen eben tatsächlich noch eine zweite Gruppe von Juristen in Russland gibt, die Recht unab- hängig von staatlichen Zwängen denken. Für die staatlichen Eliten bleiben sie allerdings Fremde, »Andersdenkende«, Feinde...

\title{
Über die Autorin
}

Caroline von Gall ist Juniorprofessorin am Institut für osteuropäisches Recht und Rechtsvergleichung der Rechtswissenschaftlichen Fakultät der Universität zu Köln

\section{ANALYSE}

\section{Der Ukraine-Krieg und die europäische Sicherheitsarchitektur}

\author{
Ulrich Kühn, Hamburg
}

\section{Zusammenfassung}

Russland ist eine Macht, die sich am »Status quo" orientiert und die Erhaltung desselben als Handlungsmaxime sieht. Dies mag, gerade angesichts der völkerrechtswidrigen Annexion der Krim und der fortgesetzten Destabilisierung der Ost-Ukraine, zunächst absurd klingen. Dabei entspricht Russlands Vorgehen in der Ukraine genau dem Kurs, den Moskau seit dem Zusammenbruch der Sowjetunion immer verfolgt hat: Wahrung des russischen Einflusses in den ehemaligen Sowjetrepubliken - dem »nahen Ausland « - und gleichzeitige Verhinderung der fortgesetzten NATO-Osterweiterung. Diese außen- und sicherheitspolitischen Prioritäten haben sich seither nicht geändert; die Strategien zur Durchsetzung der russischen Interessen hingegen schon. Vielen westlichen Sicherheitsexperten sind die Strategie-Wenden Russlands verborgen geblieben. Sie müssen nun Antworten auf die veränderte europäische Sicherheitslage finden. Vor dem Hintergrund der erneuten NATO-Russland-Konfrontation wird es dabei zunehmend schwieriger, die Instrumente kooperativer Sicherheitspolitik zu bewahren. Die kommenden Jahre werden zeigen, ob es gemeinsam gelingt, die europäische Sicherheitsarchitektur neu zu beleben.

\section{Von den 1990er Jahren zum Ukraine-Krieg}

Während der 1990er Jahre konzentrierten sich die russischen Versuche, die NATO-Osterweiterung zu verhindern, zunächst vor allem auf öffentlichen Widerspruch und hoffnungslose diplomatische Initiativen, wie etwa Gorbatschows Vision des "gemeinsamen europäischen Hauses«. Gleichzeitig »erkaufte« sich der Westen, angeführt von den USA unter Bill Clinton, in dieser Phase - auch durch eine Reihe politisch-ökonomischer Maßnahmen - die stillschweigende Zustimmung des Kremls zur NATO-Osterweiterung. So erhielt Russland die Aufnahme in diverse multilaterale Foren wie die G7 (1998) und die Asiatisch-Pazifische Wirtschaftsgemeinschaft (1998), eine institutionell prominente Verankerung der NATO-Russland-Beziehungen in Form der "Gründungsakte» (1997), die Anpassung des wichtigsten Vertragswerks zur konventionellen Rüstungskontrolle in Europa (KSE, 1999) und Washingtons Unterstützung für einen Milliardenkredit des Internationalen Währungsfonds (1999). Obwohl Boris Jelzin noch 1997 öffentlich bekundete, dass die Osterweite- rung ein »schwerer Fehler» sei, so akzeptierte Moskau doch letztlich den angebotenen Deal, um, so Jelzin, »die negativen Auswirkungen für Russland zu minimieren«. Russland war schlicht zu schwach, um sich ernsthaft Gehör zu verschaffen.

Mit Anbruch des neuen Jahrtausends änderte sich die russische Strategie. Zunächst begann die neue Regierung unter Wladimir Putin, die eigene Wirtschaft - und damit einhergehend auch den russischen Einfluss auf das "nahe Ausland — - zu konsolidieren. Gleichzeitig stellte der neue Präsident öffentlich klar, dass Russland eben dieses "nahe Ausland « als seine exklusive Einflusssphäre betrachte und damit "vitale nationale Interessen" verbinde. Davon unbeeindruckt trieb die NATO unter amerikanischer Führung zwei weitere Erweiterungsrunden (2004 und 2009) voran.

Im Jahr 2007 änderte sich die russische Strategie dann erneut, als sich das Land mit neuem Selbstbewusstsein auf der internationalen Bühne zurückmeldete. Der erste Schritt war die faktische Aufkündigung des Vertrags über konventionelle Streitkräfte in Europa (KSE) 
durch Russland. Der KSE-Vertrag hatte im Zusammenhang mit dem Ende des Kalten Kriegs die Zahl und die Ausrüstung konventioneller Streitkräfte in Europa erheblich reduziert. Mit der Vertragssuspendierung im Jahr 2007 reagierte Russland auf die Bedingung der NATO-Staaten, eine aktualisierte Version des Abkommens nur dann zu ratifizieren, wenn Russland vorher seine Truppen aus den umstrittenen Gebieten Transnistrien, Abchasien und Südossetien abziehe - Gebiete, die Moskau allesamt zum »nahen Ausland« zählt. Auf der Münchner Sicherheitskonferenz warf Wladimir Putin den USA auch deshalb vor, ihre "nationalen Grenzen in allen Bereichen überschritten« zu haben. Die Zeichen standen auf Sturm.

Als Washington unter George W. Bush dann 2008 auf den NATO-Beitritt der Ukraine und vor allem Georgiens drängte, führte eine unvorsichtige Provokation des von der US-Regierung unterstützten Präsidenten Micheil Saakaschwili zu einem fünftägigen Krieg mit Russland, der nicht nur die vollständige russischen Kontrolle über Abchasien und Südossetien bedeutete, sondern auch alle NATO-Beitrittsambitionen der georgischen Regierung begrub. Mit dem Krieg hatte Russland Tatsachen geschaffen und de facto die Tür für einen NATO-Beitritt Georgiens geschlossen. Tiflis sah sich nun auf absehbare Zeit mit zwei »eingefrorenen Konflikten« auf seinem Territorium konfrontiert.

Nur wenige Monate später präsentierte der damalige russische Präsident Medwedew den Entwurf eines Vertrags zur Neuordnung der europäischen Sicherheitsarchitektur. Das grundlegende Ziel der Russen war die vertragliche Verankerung eines russischen Vetorechts bezüglich künftiger NATO-Erweiterungen. So sah der Entwurf unter Artikel 2 vor, dass keine Vertragspartei in Aktivitäten involviert sein solle, welche die Sicherheit einer weiteren Vertragspartei signifikant beeinflusse. Stark verklausuliert bedeutete dies die Festschreibung des territorialen Status quo, da Moskau jederzeit eine weitere Osterweiterung der NATO mit Hinweis auf seine Sicherheitsinteressen hätte blockieren können. Wenig überraschend lehnten Washington und seine Alliierten diesen Vorschlag ab und delegierten die weiteren Konsultationen an die OSZE, wo die Initiative schließlich im Jahr 2010 ohne konkrete Ergebnisse versickerte.

2014 führten die Proteste auf dem Maidan-Platz in Kiew zum Sturz von Viktor Janukowytsch. Aus Sicht Moskaus bestand nun mittelfristig die Gefahr, dass die Ukraine ins "westliche Lager« wechseln könnte (inklusive EU- und NATO-Beitritt). Um dies zu verhindern, griff der Kreml auf dieselbe Strategie zurück, die bereits in Georgien zum Erfolg geführt hatte. Der einzige Unterschied war, dass Moskau auf Grund der militärischen Bedeutung des Hafens in Sewastopol diesmal keine abhängigen Satelliten schuf, sondern die Krim direkt annektierte und zu einem Teil von Russland erklärte. Zudem muss sich die Ukraine - ähnlich wie Georgien, jedoch auf deutlich höherem Gewaltniveau - seither mit einem anhaltenden Konflikt im Südosten des Landes befassen, den Russland je nach Bedarf jederzeit weiter eskalieren kann. Damit hat Moskau auf absehbare Zeit die Tür zur NATO auch für die Ukraine zugeschlagen.

Hintergrund der russischen Strategie-Wenden seit dem Zerfall der Sowjetunion war somit immer die Verhinderung der weiteren Ausdehnung der NATO nach Osten und damit der Erhalt des Status quo - zumindest so, wie Moskau ihn interpretiert. Das Ziel blieb das gleiche, die Strategien änderten sich.

\section{Und wieder geht es um Macht und Einfluss}

Stellen wir uns den Realitäten: Es geht hier um klassische Geopolitik im Stile des 19. Jahrhunderts. Die westlichen Sicherheitseliten diesseits und jenseits des Atlantiks scheinen mit dieser Erkenntnis gleichwohl ein Problem zu haben und finden keine überzeugenden Antworten auf die drängenden Fragen dieser »neuen/alten« Herausforderung.

Der prominente amerikanische Neorealist John Mearsheimer hat versucht, das russische Verhalten als Maßnahme zur Sicherstellung des "nationalen Überlebens« zu erklären (s. Mearsheimer, John J., in den Lesetipps). Laut Mearsheimer diene die Ukraine Russland demnach als "Pufferstaat mit enormer strategischer Bedeutung«, woraus er schlussfolgert, dass Moskau die Ausweitung der NATO bis in die Ukraine als existenzielle Bedrohung für die russische Sicherheit - und damit das nationale Überleben - ansehen müsse. Obgleich diese neorealistische Sicht der Dinge dabei hilft, die grundlegende Logik des russischen Handelns zu erkennen, da sie den Wirkungsgrad der NATO-Erweiterung erkennt, liegt sie in einem entscheidenden Punkt daneben: Es geht hier schlicht nicht um das "nationale Überleben« Russlands.

Sowohl die USA als auch Russland haben sich im Rahmen des (zuletzt 2010 erneuerten) START-Vertrages (»Strategic Arms Reduction Treaty») sowohl bei der Anzahl nuklearer Sprengköpfe als auch bei deren Trägersystemen erneut auf paritätische Verhältnisse verständigt. Vor dem Hintergrund dieser nuklearen Ebenbürtigkeit ist das "nationale Überleben" beider Staaten im Falle eines militärischen Angriffs des Anderen im Grunde vollständig gesichert - zumindest solange beide davon ausgehen, rational zu handeln. Wenn Russland daher wie etwa zuletzt in der Neufassung ihrer Militärdoktrin im Jahr 2014 - die NATO-Erweiterung öffentlich immer wieder als "Gefahr für ihre nationale Sicherheit" bezeichnet, ist eigentlich etwas anderes gemeint. Denn die NATO-Osterweiterung stellt wohl kaum eine exis- 
tenzielle Gefahr für die nationale russische Sicherheit dar. Sie bedeutet vielmehr eine Gefahr für Russlands Macht- und Einflussanspruch.

Zunächst stellt die befürchtete Erweiterung der NATO in Richtung Ukraine für Putin und seinen Führungszirkel eine Gefahr für den Machtanspruch nach Innen dar, da sie als möglicher Vorbote eines Regimewechsels auch in Russland gesehen wird (Stichwort "farbige Revolutionen«). Außerdem verringert sie, in der Wahrnehmung des Kreml, die politische und militärische Fähigkeit zur Machtprojektion im "nahen Ausland". Darüber hinaus entwertet sie die eigenen Vorstellungen und Konzepte zur Neuordnung des postsowjetischen Raumes, in dem Moskau für sich selbst eine wirtschaftliche und kulturelle Führungsrolle vorgesehen hat. Schlussendlich reduziert sie Russlands Rolle als selbsternannter Beschützer aller Russen, auch der außerhalb des eigenen Territoriums, und beschädigt somit Russlands Selbstbild als Großmacht nachhaltig. Der befürchtete »Verlust« der Ukraine an den Westen ist somit auch angesichts ihres historisch und kulturell wichtigen Platzes im kollektiven russischen Gedächtnis machtpolitisch ein absolutes "No go" für Moskau.

Im Kreml weiß man natürlich, dass sich hier nicht die Frage des "nationalen Überlebens« stellt, aber mit teils alarmistischen Sicherheitsbedenken lässt sich im Westen nach wie vor gut Aufmerksamkeit erregen. Der Westen hingegen weiß diese sicherheitsfokussierte Rhetorik nicht richtig zu deuten - eben weil die NATO ja keine Gefahr für die Sicherheit Russlands darstellt - und lässt dadurch wiederum auch eine ernsthafte Auseinandersetzung mit den hinter dieser Rhetorik stehenden machtpolitischen Prioritäten Russlands vermissen. Angela Merkels Wahrnehmung, dass Putin »in einer anderen Welt« lebe illustriert diese kognitive Dissonanz zwischen Russland und dem Westen auf geradezu symptomatische Weise.

Sollte Mearsheimer mit seiner Annahme Recht haben, dass Putins Denken und Handeln von neorealistischen Maximen geprägt ist, böte sich gerade diese Denkschule an, um die russische Sichtweise besser zu verstehen. Demnach hätte jede Runde der NATOErweiterung die Machtverteilung in Europa - den Status quo - nachhaltig zu Ungunsten Russlands verändert. Gemäß dieser Sicht wäre dann auch die NATO-Politik der »offenen Tür» als offensive Politik zur Veränderung des Status quo zu Ungunsten Moskaus zu deuten.

Viele westliche Sicherheitsexperten würden diese Sichtweise vermutlich rundheraus ablehnen, da sie die fortgesetzte NATO-Erweiterung weder als einen offensiv ausgerichteten Prozess, noch als eine Russland existenziell bedrohende Politik begreifen. Das Problem ist nur, dass Moskau diese Sichtweise eben nicht teilt. Folglich liegt Angela Merkel doch richtig: Die politischen Debat- ten in Moskau und den westlichen Hauptstädten werden heute tatsächlich in unterschiedlichen Welten geführt.

\section{Auswirkungen auf die europäische Sicherheitslandschaft}

Ein gewichtiger Aspekt der Putinschen Strategie zur Sicherung des Status quo ist ein schrittweiser Rückzug Russlands aus kooperativen Sicherheitsstrukturen. Seit ungefähr 2002 tritt Russland in der OSZE nicht nur als stetiger Kritiker der Organisation, sondern auch als offensichtlicher "Spoiler" auf. Als 2011 in der OSZE die Modernisierung des Wiener Dokuments über Vertrauensund Sicherheitsbildende Maßnahmen im militärischen Bereich verhandelt wurde, war es an Moskau, beispielsweise weitreichendere Maßnahmen zur Überwachung von Militärmanövern zu verhindern. Auf die faktische Aufkündigung des KSE-Vertrags im Jahr 2007 folgte im März 2015 das endgültige Ausscheiden der russischen Delegation aus dem KSE-Konsultationsmechanismus.

Seit 2008 verdächtigen die USA Moskau, an der Entwicklung einer verbotenen bodengestützten Mittelstreckenrakete zu arbeiten. 2014 machte Washington diese Vorwürfe dann öffentlich und bezichtigt seitdem die russische Seite, den Vertrag über das Verbot von nuklearen Mittelstreckensystemen (INF-Vertrag) zu unterlaufen. Mit dem russischen Einmarsch auf der Krim brach Moskau auch seine gegenüber der Ukraine eingegangenen Sicherheitsgarantien aus dem Budapester Memorandum von 1994. Damals hatte sich Kiew verpflichtet, seine knapp 2.000 Nuklearsprengköpfe nach Russland zu überführen. Im Gegenzug sicherte Moskau der Ukraine die volle territoriale Integrität zu. Parallel zu diesen bedenklichen Entwicklungen häufen sich verdeckte oder offene Drohungen aus Moskau, im Krisenfall die russischen Nuklearstreitkräfte einzusetzen.

Die Annexion der Krim und der darauf folgende Krieg in der Ukraine stehen somit sinnbildlich für den fast vollständigen Zusammenbruch kooperativer Sicherheitsstrukturen in Europa. Was in mühsamer diplomatischer Kleinstarbeit über viele Jahrzehnte errichtet wurde, erodiert seit nunmehr 15 Jahren zunehmend. Dabei ist der Krieg in der Ukraine bei Weitem nicht das alleinig auslösende Moment - noch ist der Westen unschuldig an dieser Entwicklung. Zu lange haben westliche Staatenlenker den Zeichen der Zeit nicht genug Aufmerksamkeit geschenkt. Zu häufig bestimmten eigene Machtinteressen - wie im Falle der amerikanischen KSE-Politik - den Umgang mit den Instrumenten kooperativer Sicherheit.

Gleichwohl hat Moskau mit seinem Vorgehen in der Ukraine nicht nur diverse "rote Linien« überschritten. Viel schwerer wiegt die russische Entwertung der normativen Grundlagen kooperativer Sicherheit - festgelegt in den diversen Dokumenten der KSZE bzw. der heuti- 
gen OSZE. Prinzipien wie territoriale Integrität, staatliche Souveränität und der Nichteinsatz militärischer Gewalt galten über Jahrzehnte als Primärvektoren einer gemeinsamen europäischen Sicherheitsordnung. Diese stehen nun offen zur Disposition.

Die konkreten Auswirkungen dieser Politik verheißen nichts Gutes für die kommenden Jahre. Ohne moderne und allgemein akzeptierte und eingehaltene Abkommen kooperativer Sicherheit wird es schwierig, dem militärischen Primat gegenseitiger Abschreckungsstrategien nicht erneut die Oberhand zu lassen. Dies gilt sowohl für sub-regionale Konflikte wie derzeit in der Ukraine, als auch für die weitere Konfrontation zwischen der NATO und Russland. Ohne den KSE-Vertrag ist dringend gebotene Zurückhaltung und Transparenz im konventionellen militärischen Bereich nicht mehr gewährleistet. Im Falle eines Auseinanderbrechens des INF-Vertrags droht Europa eine mögliche Re-Nuklearisierung. Erste Stimmen in den USA drängen bereits in diese Richtung. Europa stehen schwierige sicherheitspolitische Entscheidungen bevor.

\section{Harte Entscheidungen stehen an}

Eine Strategie, die ausschließlich auf das Bestrafen Russlands setzt, birgt mittelfristig erhebliche Risiken. Denn erstens ist eine konstruktive Zusammenarbeit mit Russland, sowohl für die Sicherheit Europas als auch die der USA, schlicht unentbehrlich. Dies zu negieren, hieße, die Realitäten zu verkennen. Und zweitens fehlt der jetzigen Strategie der Bestrafung ein zentrales Element: ein realistisches Ziel. Zwar fügen die verhängten Sanktionen der russischen Wirtschaft unzweifelhaft schweren Schaden zu, aber was soll damit letztlich erreicht werden? Etwa der Rückzug Russlands aus der Ukraine, inklusive der Krim? Beides dürfte auf diesem Weg kaum gelingen. Oder ist das Fernziel möglicherweise gar ein Regimewechsel in Moskau? Aber was kommt danach? Und wer kann vorhersagen, ob der nächste Kremlchef kooperativer sein wird - oder nicht vielmehr unberechenbarer?

Die Formulierung einer besseren Strategie für den Umgang mit Russlands Macht- und Sicherheitsinteressen wird jedenfalls einige bittere Einsichten und harte Entscheidungen erfordern. Das grundsätzliche Problem ist, dass es nach dem Ende des Kalten Kriegs nicht gelang, gemeinsam mit Russland eine Sicherheitsarchitektur zu errichten, die gleichermaßen den westlichen wie auch den russischen Macht- und Sicherheitsinteressen entspricht. Die europäische Sicherheit braucht folglich einen Neustart. Aber wie kann ein solcher Neustart gelingen wenn beide Seiten noch immer zu wenig Verständnis für die jeweils andere Seite an den Tag legen? Und wie soll ein gemeinsamer Ansatz aussehen wenn Moskau sich zunehmend aus den bestehenden kooperativen Formaten zurückzieht?

Mittelfristig ist der derzeitige Zustand jedenfalls für keine der Seiten haltbar. Der Westen kann sich grundsätzlich entweder für eine vorsichtige Wiederannäherung an Russland, für eine kollektive Eindämmung Moskaus oder für eine möglichst geschickte Kombination aus beiden Strategien entscheiden.

Für eine gegenseitige Wiederannäherung gibt es gute Gründe. Für den Westen würde dies jedoch bedeuten, sich den russischen Machtansprüchen und der diskussionswürdigen russischen Selbstwahrnehmung als einer "exzeptionellen und singulären Weltmacht" stellen zu müssen. Praktisch hieße das beispielsweise, (selbst)kritisch die bisherige und zukünftige NATO-Politik der "offenen Tür« zu diskutieren, gemeinsam mit Russland über den Status und die Sicherheitsinteressen postsowjetischer Staaten wie der Ukraine, der Republik Moldau, Georgiens und Aserbaidschans nachzudenken, eine Politik, die ausschließlich auf die innere Transformation Russlands zielt, hintanzustellen und, nicht zuletzt, rüstungskontrollpolitische Antworten für das schwierige NATO-Russland-Verhältnis zu finden. Sich konstruktiv mit diesen Themen zu befassen, hieße keineswegs, sich die Sichtweise der derzeitigen russischen Eliten zu eigen zu machen oder russischen Interessen blind zu entsprechen.

Für Moskau wiederum würde es bedeuten, sein völkerrechtswidriges Vorgehen in den Ländern des »nahen Auslands« zu beenden und einen gesichtswahrenden Weg zurück in die Gemeinschaft europäischer Werte und der damit verbundenen Sicherheitsinstitutionen zu finden. Gerade vor dem Hintergrund der eigenen sozioökonomischen Schwäche und der vergleichsweise exorbitanten Stärke Chinas kann Russlands Zukunft nicht ausschließlich in Asien liegen. Noch weniger wird Russland einen nationalen Rückzug in die Politik pseudosowjetischer Autarkie durchstehen. Russlands Zukunft liegt in Europa. Es ist an den Herren des Kreml, dieser Einsicht politische Geltung zu verschaffen.

Über den Autor

Ulrich Kühn ist wissenschaftlicher Mitarbeiter am Institut für Friedensforschung und Sicherheitspolitik an der Universität Hamburg und Koordinator der deutsch-russisch-amerikanischen Expertenkommission zu »Deep Nuclear Cuts«. 
Lesetipps

- Charap, Samuel, Jeremy Shapiro: A New European Security Order: The Ukraine Crisis and the Missing Post-Cold War Bargain, Paris: FRS, 8. Dezember 2014; <http://www.frstrategie.org/barreFRS/publications/notes/2014/201415. pdf>.

- Engström, Maria: Contemporary Russian Messianism and New Russian Foreign Policy, in: Contemporary Security Policy, 35, 2014, Nr. 3, S. 356-379.

- Kühn, Ulrich: Medvedev's Proposals for a New European Security Order. A Starting Point or the End of the Story? in: Connections, The Quarterly Journal, 9, 2010, Nr. 2, S. 1-16; <http://connections-qj.org/article/ medvedevs-proposals-new-european-security-order-starting-point-or-end-story>.

- Mearsheimer, John J.: Why the Ukraine Crisis is the West's Fault: The Liberal Delusions That Provoked Putin, in: Foreign Affairs, 93.2014, Nr. 5, S. 77-89; <https://www.foreignaffairs.com/articles/russia-fsu/2014-08-18/ why-ukraine-crisis-west-s-fault $>$.

\section{Leitgedanken für die nun notwendige Russlandpolitik}

\section{Zusammenarbeit, soweit wie möglich. Gefahrenabwehr, soweit wie nötig}

Karsten D. Voigt, Berlin

$\mathrm{M}$ anchmal sieht man aus der Ferne klarer. Vor einigen Wochen sprach ich mit chinesischen Ukraineund Russland-Experten. Deren Analyse: Die Konflikte auf der Krim und in der Ost-Ukraine werden zu einer größeren Zäsur in der europäischen und internationalen Politik führen als die Terrorangriffe vom 9. September. Ich widersprach, weil es unser Ziel bleiben sollte, eine gesamteuropäische Friedensordnung unter Einbeziehung Russlands zu etablieren. Aber die mehr als ernüchternden Erfahrungen der vergangenen Monate lehren, dass dieses Ziel in weite Ferne gerückt ist. Diese negative Entwicklung aber resultiert nicht in erster Linie aus der Politik des Westens.

Nach dem überwiegend friedlichen Zerfall der Sowjetunion hatte sich die gesamteuropäische Zusammenarbeit vertieft und beschleunigt: Russland wurde in den Europarat aufgenommen und zum Partner von EU und NATO. Handel und Kulturaustausch nahmen zu, das Netz der gesamteuropäischen Beziehungen wurde dichter. Das Ziel einer Vollmitgliedschaft Russlands in der EU und NATO war zwar nie realistisch, aber der Westen bemühte sich, wenn auch nicht konsequent genug, um eine engere Kooperation. Die Große Koalition begann noch im Herbst 2013 mit der Absicht, die Zusammenarbeit mit Russland durch neue Initiativen zu vertiefen.

\section{Russland hat sich geändert}

Russlands Führung behauptet heute, ihre außenpolitische Neuorientierung sei eine Reaktion auf die Politik des Westens und hier vor allem der USA. Ja, die Vereinigten Staaten und die EU haben Fehler im Umgang mit Russland gemacht. Aber diese Fehler rechtfertigen weder die Annexion der Krim, noch die politische, militärische und finanzielle Unterstützung der Separatisten in der Ost-Ukraine.

Die Gründe für die außenpolitische Neuorientierung Russlands liegen in der Innenpolitik: Präsident Putin betrachtet den Zerfall der Sowjetunion und das Ende des Sowjet-Kommunismus nicht als historische Chance für den Aufbau eines modernen und demokratischen Russland, sondern "als größte geostrategische Katastrophe des zwanzigsten Jahrhunderts«. Putins Russland will international nicht als das Land anerkannt werden, das es heute ist, sondern als das, was es einmal war: als Imperium. Das Streben nach Erhalt und Wiedergewinnung von Einflusszonen wird von den meisten Nachbarn als russischer Revisionismus wahrgenommen.

Demgegenüber wird eine "Verwestlichung« des Landes als Bedrohung angesehen. Diese Sicht verbindet die gegenwärtige Führung Russlands geistig und politisch mit den antiwestlichen linken und rechten Rändern des europäischen Parteienspektrums. Solange die russische Führung von dieser Weltsicht geprägt ist, wird ihre Politik für das übrige Europa ein Problem bleiben. Dennoch sollten unsere konstruktiven gesamteuropäischen Ziele bestehen bleiben.

Unsere Sympathie und Solidarität sollte deshalb den nach Demokratie strebenden Kräften in Russland gel- 
ten, auch wenn sie zurzeit eine Minderheit darstellen. Andererseits kann das Land nicht gegen den Willen seiner politischen Führung und erst recht nicht gegen den Willen der Mehrheit des russischen Volkes von außen verändert werden. Die Mittel der Außen- und Sicherheitspolitik können den negativen Folgen der heutigen Politik Russlands für die internationalen Beziehungen entgegenwirken. Bevor es aber zu einer tiefgreifenden Wende in der russischen Politik kommt, dürften Jahre hoffentlich nicht Jahrzehnte - vergehen. In der vor uns liegenden Phase wird es nicht mehr um eine Politik der sich ergänzenden Kooperation und Integration gehen. Stattdessen könnte das Motto für die nun notwendige Russlandpolitik lauten: Zusammenarbeit, wo möglich Gefahrenabwehr, wo nötig.

\section{Punktuelle Zusammenarbeit}

Russland, die EU und die USA sollten punktuell weiter zusammenarbeiten, etwa bei den Verhandlungen über das iranische Atomprogramm oder beim gemeinsamen Vorgehen gegen internationalen Terrorismus. Wenn die russische Führung die Vereinbarungen von Minsk einhält, sollten auch die Wirtschaftssanktionen aufgehoben werden. Die Ukraine, Russland und die EU können die sicherheitspolitischen Bestimmungen des Minsker Abkommens nur gemeinsam verwirklichen, und sie müssen zusammen über mögliche negative wirtschaftliche Folgen des Assoziationsabkommens sprechen.

Der Krieg in der Ost-Ukraine sollte Anlass genug sein, die OSZE auszubauen und sie handlungsfähiger zu machen. Es sollte geprüft werden, ob in der OstUkraine OSZE-Blauhelme eingesetzt werden können. Ob die russische Führung zu einer Verbesserung der bisherigen Regeln und zu einer größeren Transparenz bei der Rüstungskontrolle bereit ist, sollte spätestens während des deutschen OSZE-Vorsitzes 2016 ausgelotet werden. Dadurch würden in einer von Misstrauen und Konflikten geprägten Umgebung Elemente kooperativer Sicherheit gestärkt.

Russland wird aufgrund seines Verhaltens heute von den meisten seiner Nachbarn als Risiko angesehen. Diese skeptische Einschätzung ist verständlich und wird erst weichen, wenn die Führung Russlands nicht nur ihre Rhetorik, sondern auch ihr Verhalten ändert. Vor allem muss sie ihre Versuche der Destabilisierung der Ukraine beenden. In einem auf diese Weise positiv veränderten politischen Umfeld, könnten dann Verhandlungen zwischen Europäischer und Eurasischer Union erfolgreich sein.

Viele sprechen heute von einem neuen Kalten Krieg. Das ist einerseits verständlich. Besser jedoch wäre es, wenn wir für die heutige Auseinandersetzung auch neue Begriffe entwickeln würden. Denn einerseits handelt es sich bei dem Konflikt in der Ost-Ukraine um einen heißen Krieg. Andererseits sind wir - im Unterschied zum Kalten Krieg - zumindest auf dem Papier durch gemeinsame friedenspolitische und demokratische Werte und Normen miteinander verbunden. Wir sollten diese Institutionen, Verträge und Vereinbarungen nicht leichtfertig aufs Spiel setzen. Wenn Russland aber seinerseits dieses Netzwerk der Beziehungen beschädigt, werden wir den Schaden nicht einseitig beheben können. Deswegen war es richtig, dass die Parlamentarische Versammlung des Europarates das Stimmrecht der russischen Delegation suspendiert hat.

Das heutige Russland besitzt nach wie vor ein mit den USA vergleichbares Arsenal von Atomwaffen. Doch vergleicht man alle der NATO zur Verfügung stehenden militärischen Potentiale mit den russischen Fähigkeiten, besteht eine eindeutige Überlegenheit der NATO - trotz der Modernisierungen der militärischen Fähigkeiten Russlands in den vergangenen Jahren. Diese Überlegenheit käme bei Konflikten mit NATO-Staaten in der unmittelbaren russischen Nachbarschaft zum Tragen. Auf solche Sicherheitsgarantien können sich hingegen die kleineren Nachbarn Russlands, die nicht Mitglied der NATO sind, nicht verlassen. Hier wirkt die regionale militärische Überlegenheit Russlands, von der die unterstützten Separatisten profitieren.

Deutschland hatte seinerzeit gegen die NATO-Mitgliedschaft Georgiens und der Ukraine ein Veto eingelegt. Umso mehr sollte sich Deutschland um eine nichtmilitärische Stabilisierung der Ukraine bemühen. Hierzu gehört die Bereitschaft zur wirtschaftlichen Hilfe für die Ukraine und zu Wirtschaftssanktionen gegenüber Russland. Allerdings wage ich vorauszusagen: Wenn sich die russische Führung und die Separatisten nicht an die Vereinbarungen von Minsk halten, werden die USA und einige europäische NATO-Staaten mit einer militärischen Unterstützung der Ukraine beginnen.

Die deutsche Politik kann in Abwägung aller Risiken gegen eine militärische Unterstützung der Ukraine sein. Man sollte aber nicht bestreiten, dass das Streben der Ukraine nach einer Verbesserung seiner Verteidigungsfähigkeit völlig legitim ist. Der Streit um taktische Mittel sollte die gemeinsame Strategie gegenüber Russland nicht gefährden. Deutschland sollte auch künftig keine Politik gegenüber Moskau betreiben, bei der die Interessen seiner östlichen und westlichen Nachbarn übergangen würden.

Während des Kalten Krieges beanspruchte die von der Sowjetunion vertretene kommunistische Ideologie weltweite Geltung. Ihre Attraktivität ließ im Laufe der Jahrzehnte zwar nach, doch blieb der globale Anspruch bestehen. Heute wehrt sich die politische Führung Russ- 
lands gegen den universalistischen Anspruch "westlicher" Werte. Keines der aus diesem Sammelsurium von Ressentiments entstandenen Konzepte ist jedoch geeignet die Probleme des 21. Jahrhunderts zu lösen. Die Ideologie der russischen Führung wirkt nur dort, wo Russland Macht ausübt und nicht etwa, weil sein Gesellschaftsmodell attraktiv wäre. Die EU sollte im Gegensatz dazu zur Stabilisierung der Ukraine beitragen und in eine Politik investieren, die die Attraktivität Europas in den Augen der ukrainischen Bürger stärkt.

Eine ausführlichere Version dieses Beitrags erschien unter dem gleichen Titel in der Aprilausgabe der "Berliner Republik" (2015, Nr. 2, S. 22-24; <http:// www.b-republik.de/aktuelle-ausgabe/zusammenarbeit$\%$ E2\%80\%93-so-weit-wie-moeglich-gefahrenabwehr\%E2\%80\%93-so-weit-wie-noetig >).

\section{Über den Autor}

Karsten D. Voigt war von 1976 bis 1998 Mitglied des Bundestags, seit 1983 als außenpolitischer Sprecher der SPDFraktion und bis 1998 Vorsitzender der deutsch-russischen Parlamentariergruppe. Von 1999 bis 2010 war er Koordinator der Bundesregierung für die deutsch-amerikanische Zusammenarbeit. Karten Voigt ist Mitglied des Präsidiums der Deutschen Gesellschaft für Auswärtige Politik.

\section{UMFRAGE}

\section{Die Russland-Ukraine-Krise in russischen Umfragen}

\section{Grafik 1: Was für Ziele in der Beziehung zu der Ukraine sollte sich Russland Ihrer Meinung nach setzen? (mehrere Antwortmöglichkeiten)}

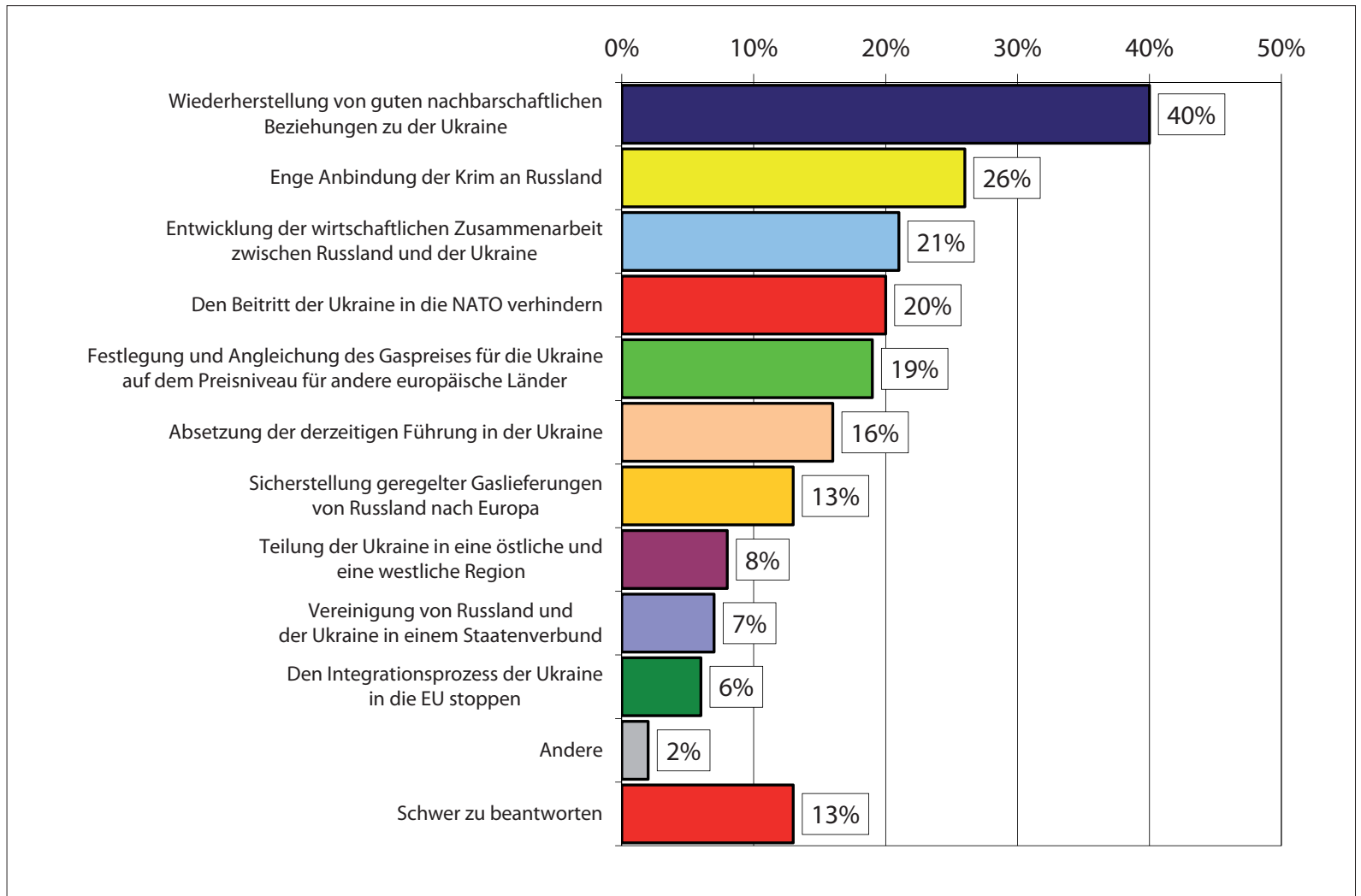

Quelle: Umfrage des Lewada-Zentrums vom 17.-20. April 2015, N=1600. Veröffentlicht am 5. Mai 2015 unter: <http://www.leva da.ru/print/05-05-2015/ukrainskii-krizis> 
Grafik 2: Was vermuten Sie, gibt es aufseiten der Kämpfer der Donezker und Luhansker Volksrepubliken auch russische Staatsbürger? (April 2015)

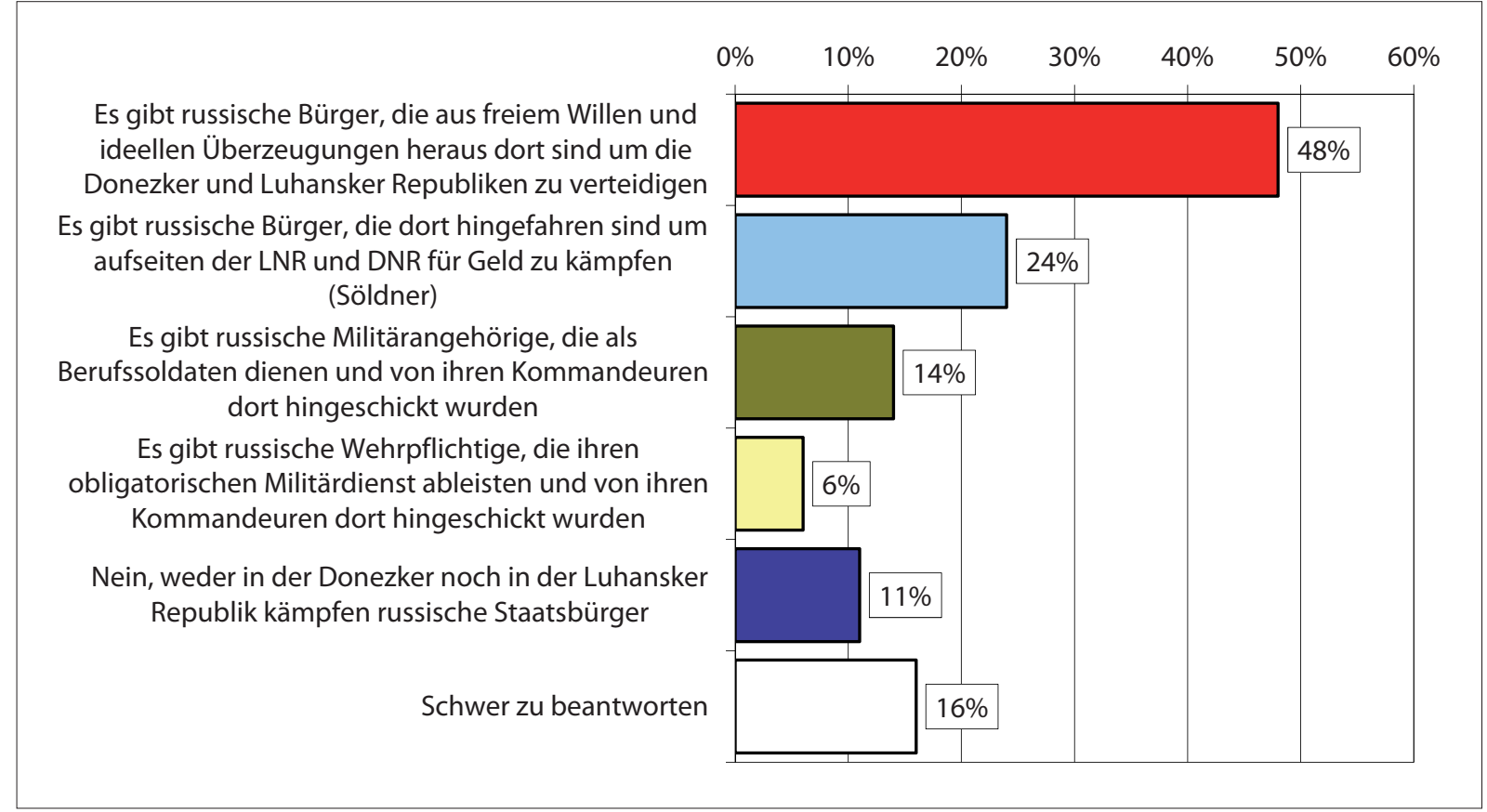

Quelle: Umfrage des Lewada-Zentrums vom 17.-20. April 2015, N=1600. Veröffentlicht am 5. Mai 2015 unter: <http://www.leva da.ru/print/05-05-2015/ukrainskii-krizis>

Grafik 3: Wofür steht Ihrer Meinung zufolge die Vereinigung der Krim mit Russland?

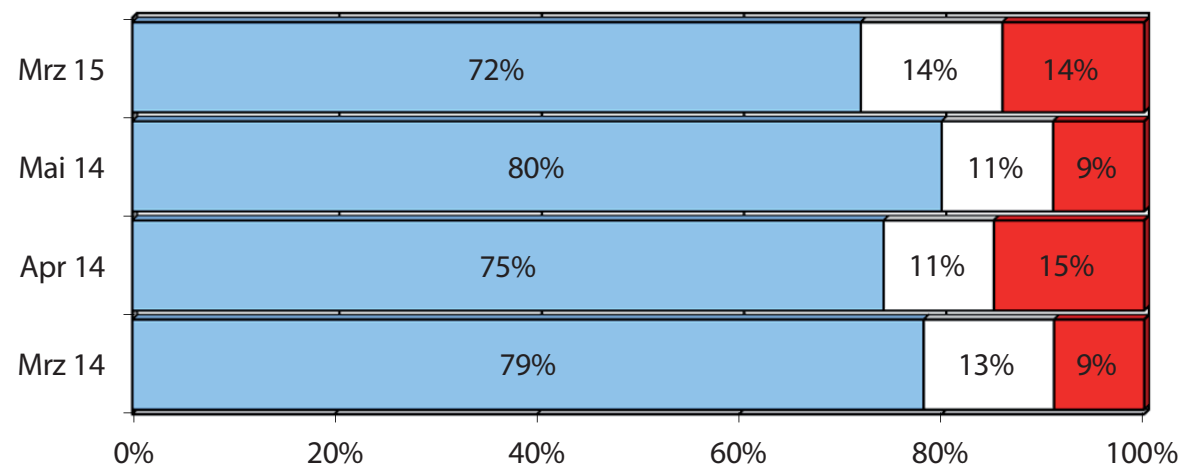

口Dafür, dass Russland zurückkehrt zu seiner traditionellen Rolle als »Großmacht« und so seine Interessen im post-sowjetischen Raum bekräftigt

口Schwer zu beantworten

口Für zunehmenden Größenwahn der russischen Führung, die sich darum bemüht die Bevölkerung von realen sozialen und ökonomischen Problemen, von Korruption und Unzufriedenheit mit der russischen Staatsführung abzulenken

Quelle: Umfrage des Lewada-Zentrums vom 13.-16. März 2015, N=1600. Veröffentlicht am 24. März 2015 unter: <http://www.le vada.ru/print/23-03-2015/krym-i-rasshirenie-rossiiskikh-granits> 
Grafik 4: Ist die Entscheidung Russlands die Krim einzugliedern Ihrer Meinung nach endgültig und unwiderruflich - oder kann diese Entscheidung revidiert werden? (geschlossene Frage, eine Antwortmöglichkeit)

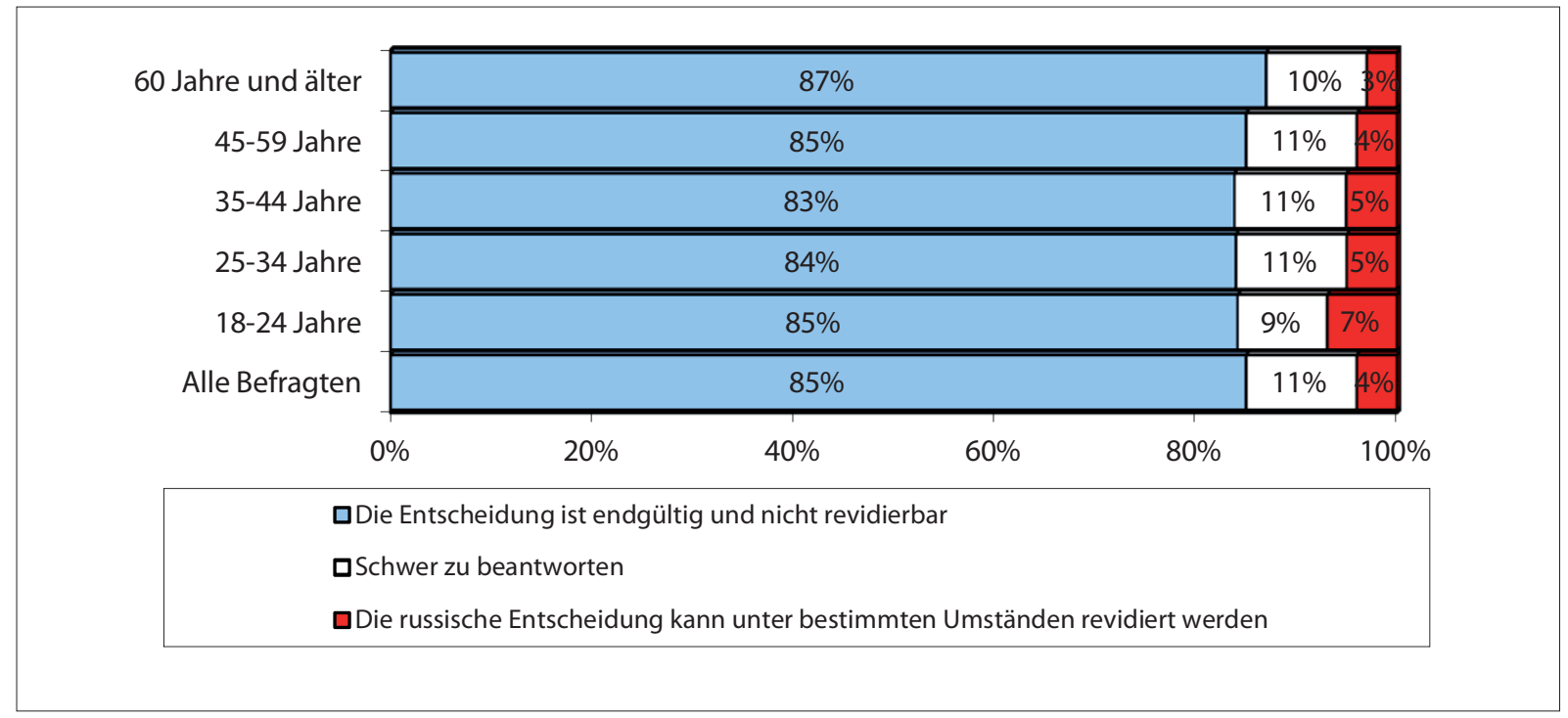

Quelle: Umfrage des Meinungsforschungsinstituts WZIOM vom 21.-22. Februar 2015, N=1600. Veröffentlicht am 22. März 2015 unter: <http://wciom.ru/index.php?id=459\&uid=115184>

\section{Russlands internationale Rolle}

Grafik 5: Welche Rolle spielt Russland Ihrer Meinung nach derzeit in der Lösung internationaler Probleme?

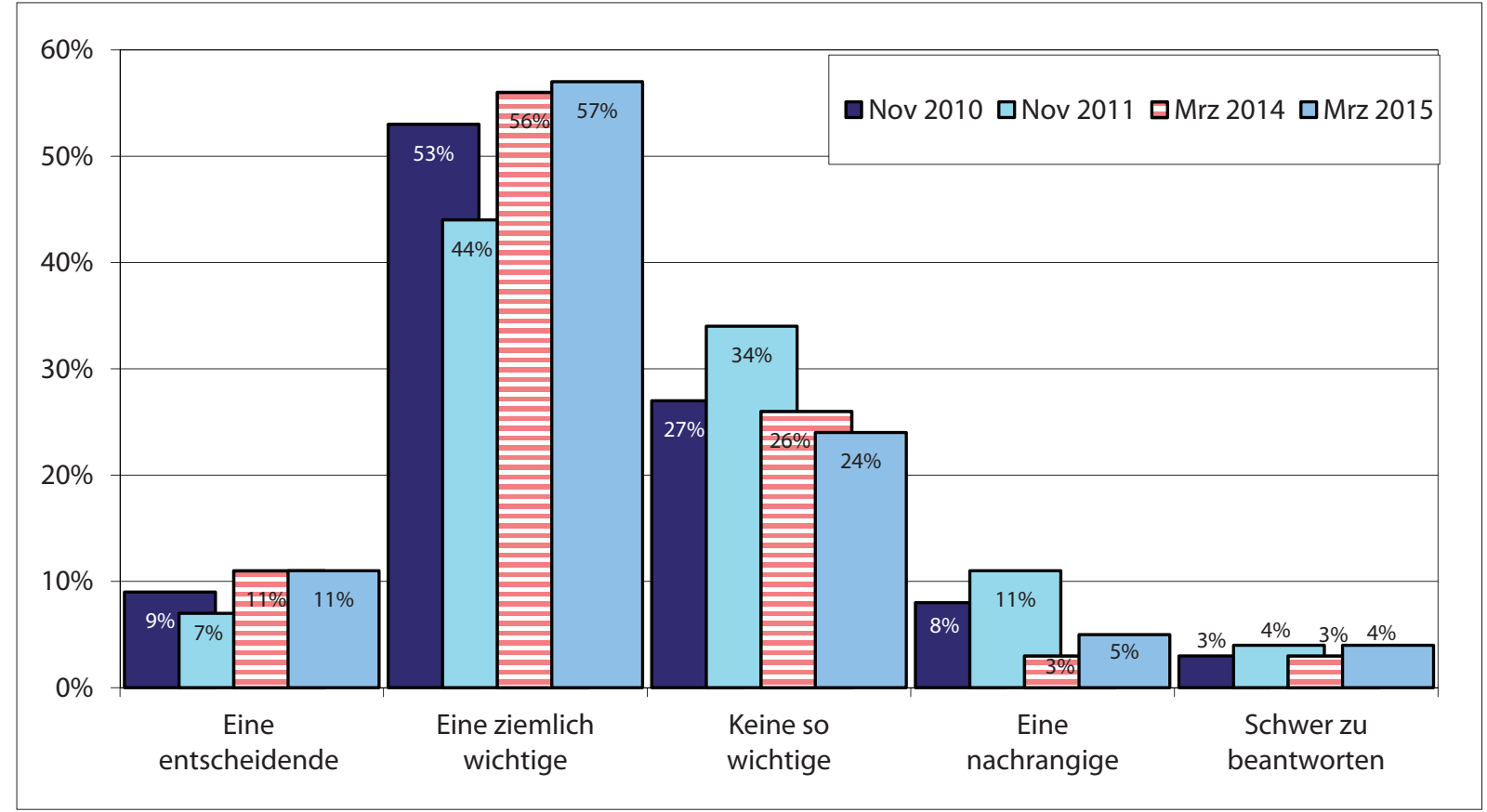

Quelle: Umfrage des Lewada-Zentrums vom 13.-16. März 2015, N=1600. Veröffentlicht am 24. März 2015 unter: <http://www.le vada.ru/print/23-03-2015/pozitsii-rossii-na-mezhdunarodnoi-arene> 
Grafik 6: Was für eine Politik gegenüber den westlichen Staaten würden Sie am ehesten befürworten:

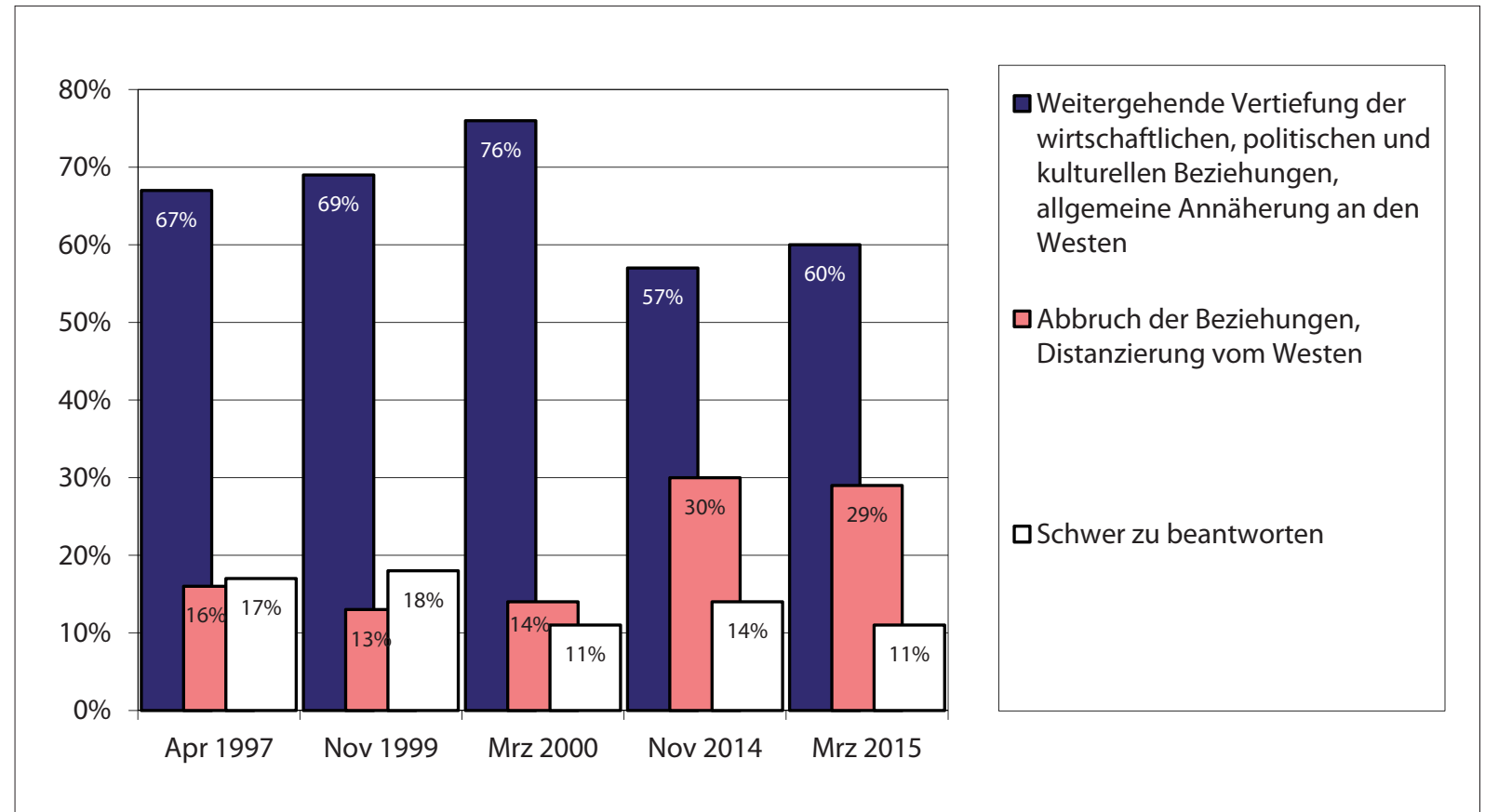

Quelle: Umfrage des Lewada-Zentrums vom 13.-16. März 2015, N=1600. Veröffentlicht am 24. März 2015 unter: <http://www.le vada.ru/print/23-03-2015/pozitsii-rossii-na-mezhdunarodnoi-arene>

Grafik 7: Wie schätzen Sie die tatsächliche derzeitige Gefährdung Russlands durch innere und äußere Feinde ein?

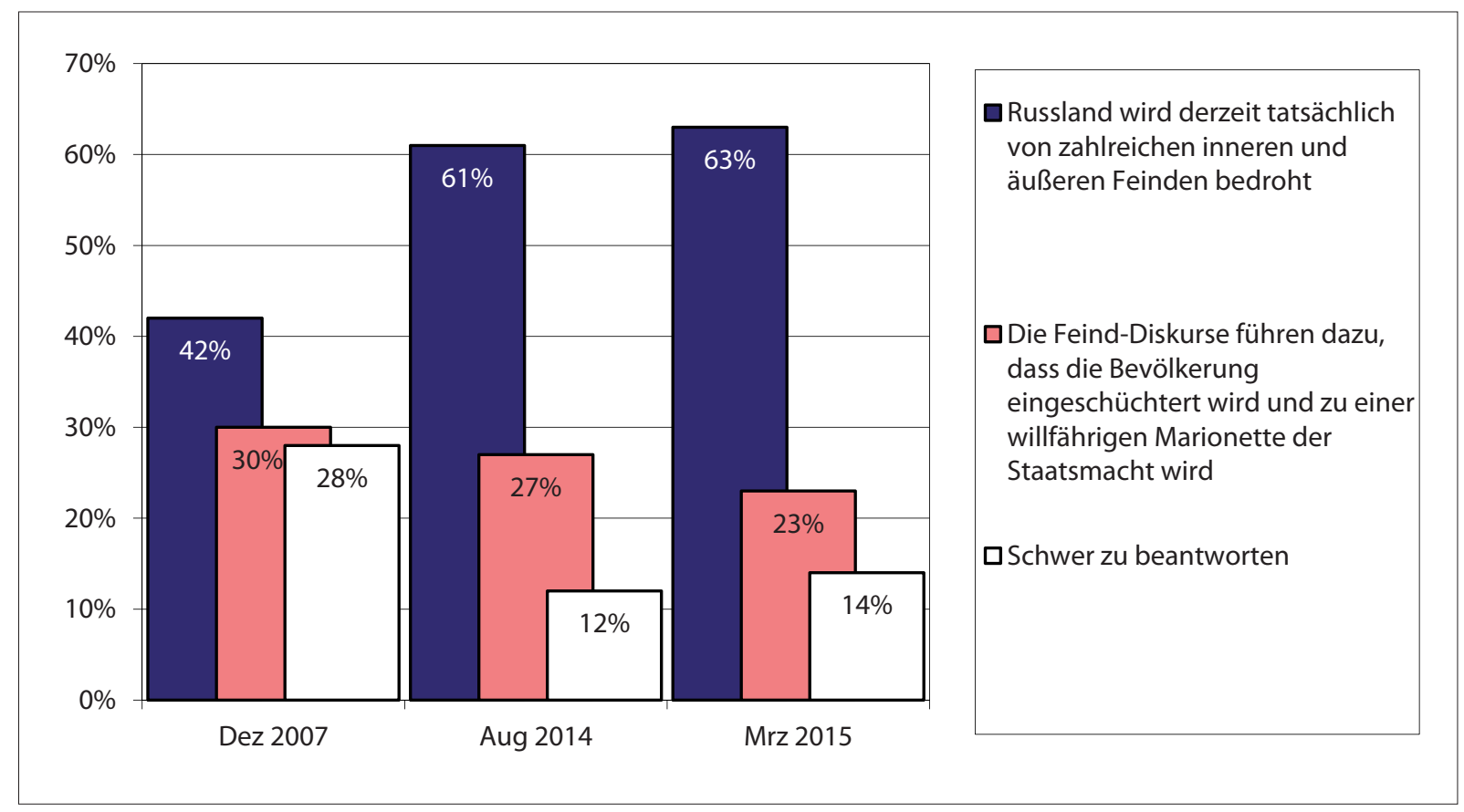

Quelle: Umfrage des Lewada-Zentrums vom 13.-16. März 2015, N=1600. Veröffentlicht am 24. März 2015 unter: <http://www.le vada.ru/print/23-03-2015/pozitsii-rossii-na-mezhdunarodnoi-arene> 


\section{Russlands Weg}

Grafik 8: Was meinen Sie, auf welchem historischen Weg sollte Russland sich bewegen?

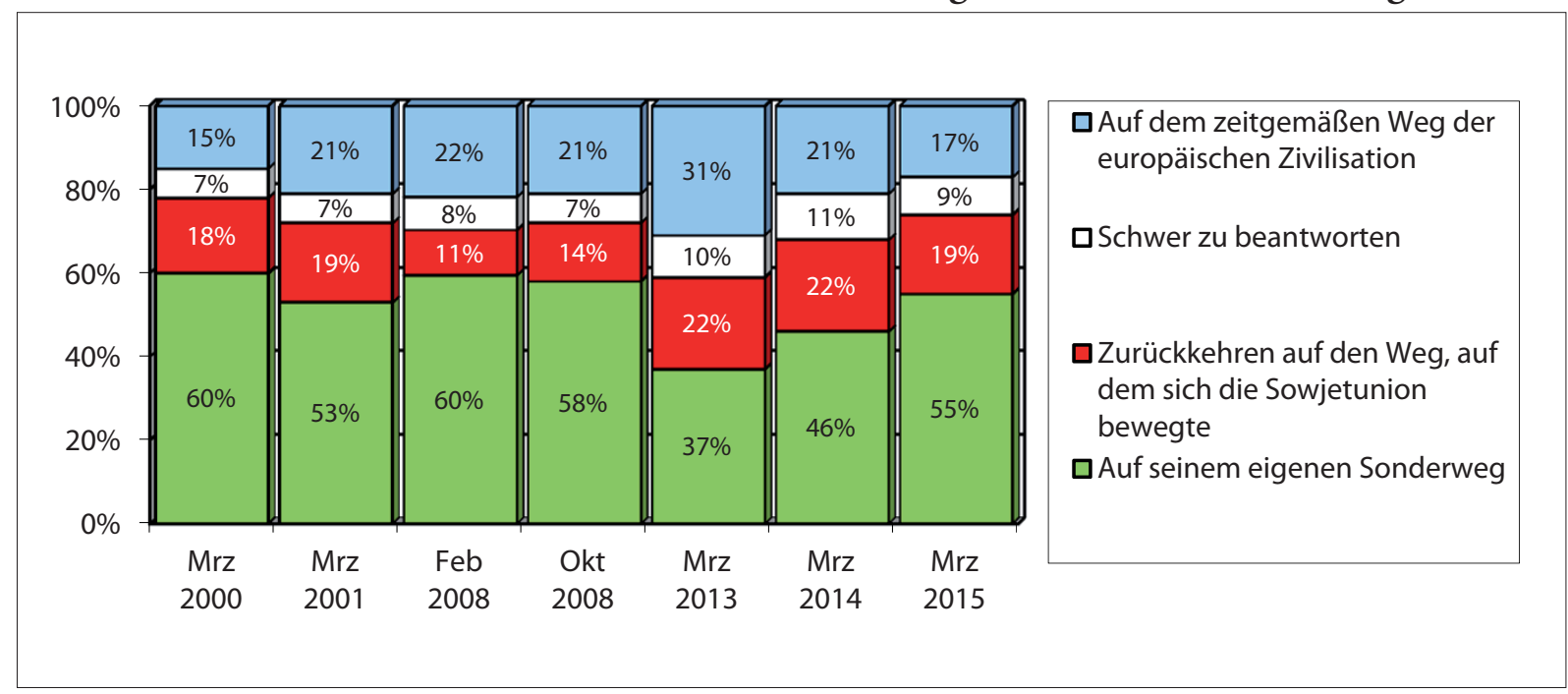

Quelle: Umfrage des Lewada-Zentrums vom 20.-23. März 2015, N=1600. Veröffentlicht am 23. April 2015 unter: <http://www.le vada.ru/print/21-04-2015/istoricheskii-put-rossii>

\section{Jahre Sieg im »Großen Vaterländischen Krieg«}

Grafik 9: Wie sehen Sie den 9. Mai - handelt es sich dabei Ihrer Meinung nach am ehesten um ...

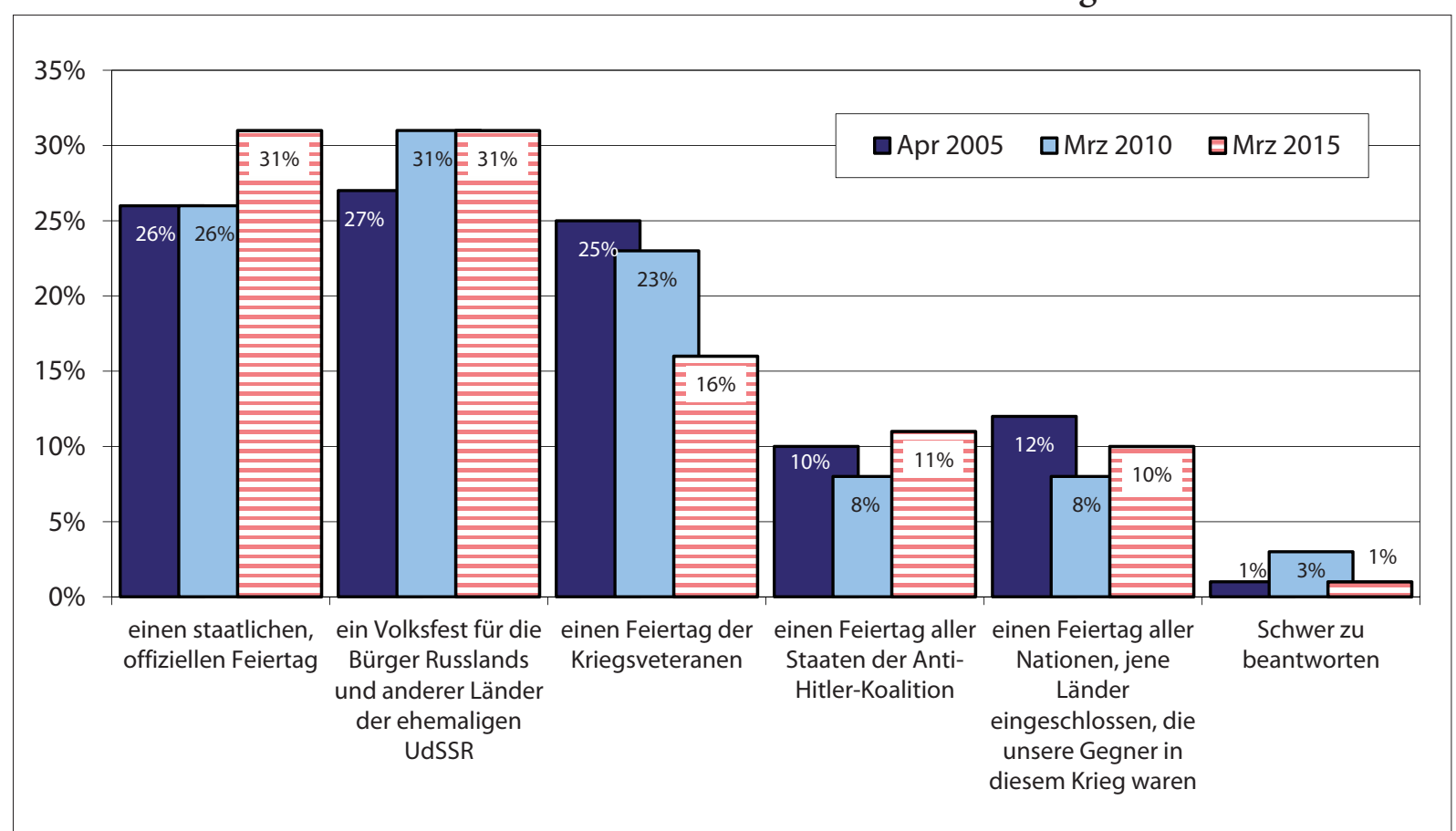

Quelle: Umfrage des Lewada-Zentrums vom 20.-23. März 2015, N=1600. Veröffentlicht am 1. Mai 2015 unter: <http://www.leva da.ru/print/29-04-2015/velikaya-otechestvennaya-voina> 
Grafik 10: Trifft es zu, dass einer Ihrer nächsten Verwandten in den Jahren des Großen Vaterländischen Krieges ... (mehrere Antwortmöglichkeiten)

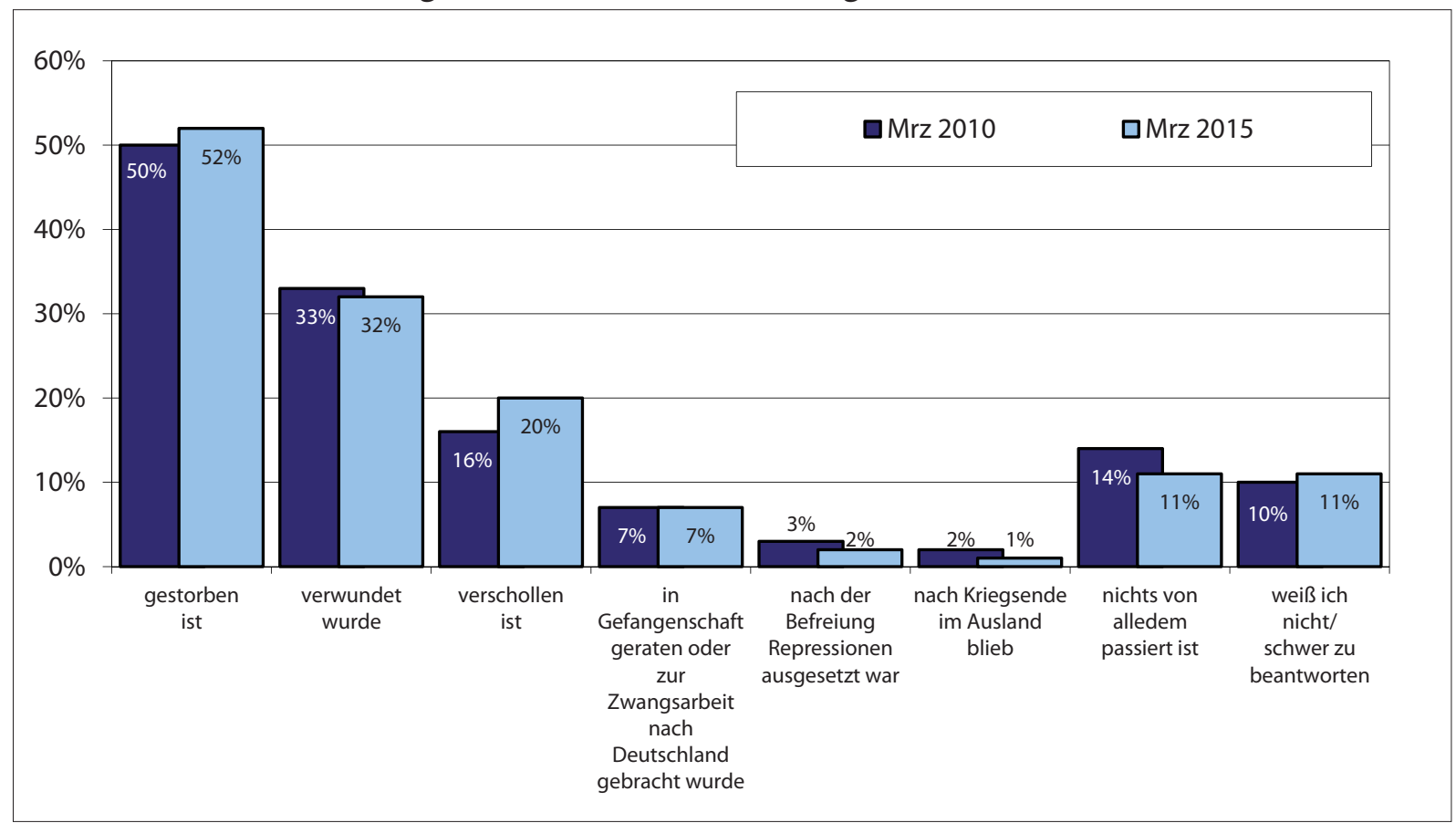

Quelle: Umfrage des Lewada-Zentrums vom 20.-23. März 2015, N=1600. Veröffentlicht am 1. Mai 2015 unter: <http://www.leva da.ru/print/29-04-2015/velikaya-otechestvennaya-voina>

Grafik 11: Am 9. Mai wird in Moskau und in anderen russischen Städten die Siegesparade abgehalten. Worin besteht Ihrer Meinung nach der Sinn dieser Parade? (offene Frage, beliebige Anzahl an Antworten)

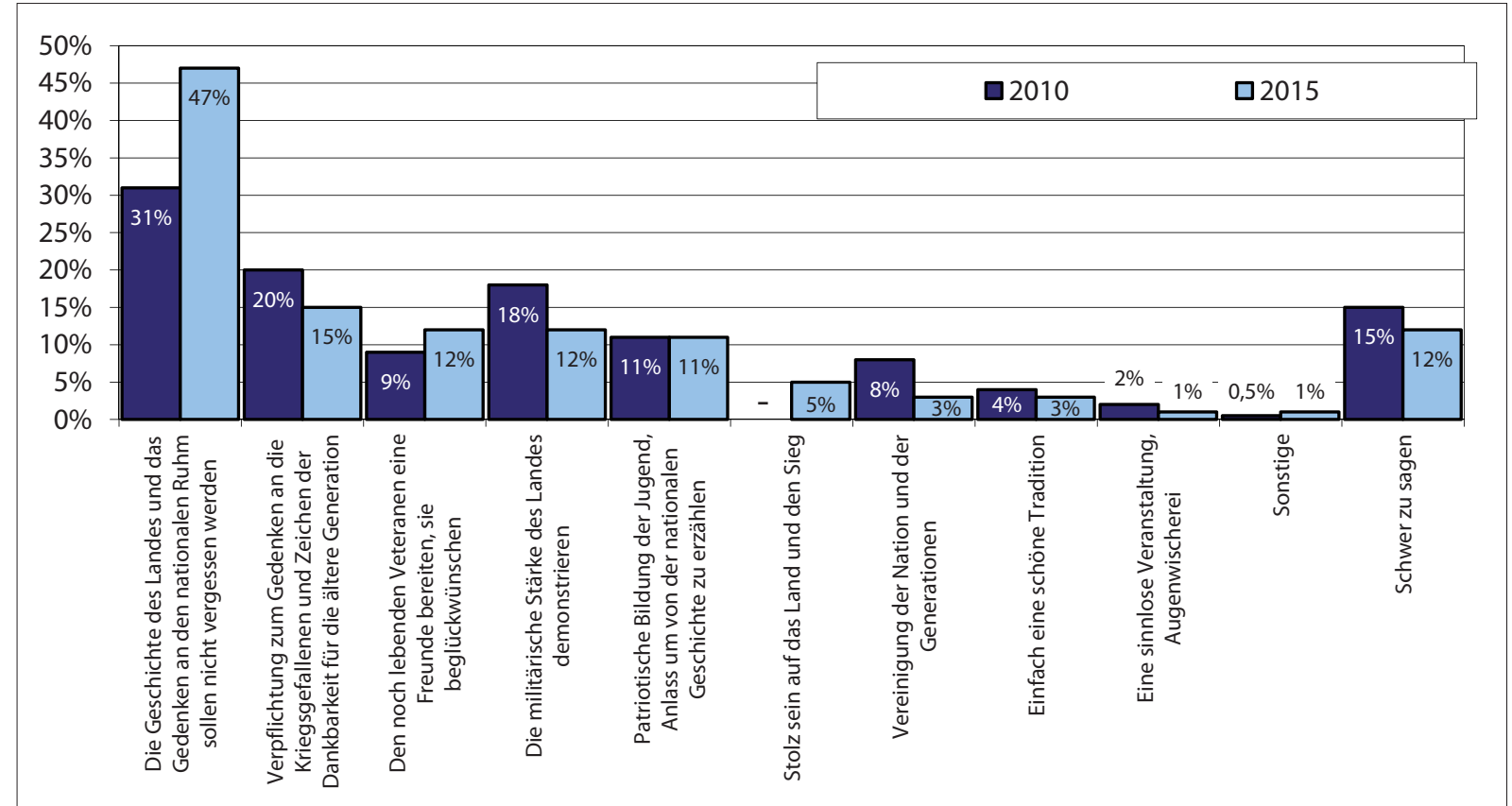

Quelle: Umfrage des WZIOM Meinungsforschungsinstituts vom 4.-5. April 2015, N = 1600. Veröffentlicht am 1. Mai 2015 unter: $<$ http://wciom.ru/index.php?id=236\&uid=115233> 
Grafik 12: Wie Sie vielleicht wissen oder gehört haben, hat ein Teil der ausländischen Staatschefs aus den am Zweiten Weltkrieg beteiligten Ländern ihren Besuch zu den Feierlichkeiten am 9. Mai abgesagt.

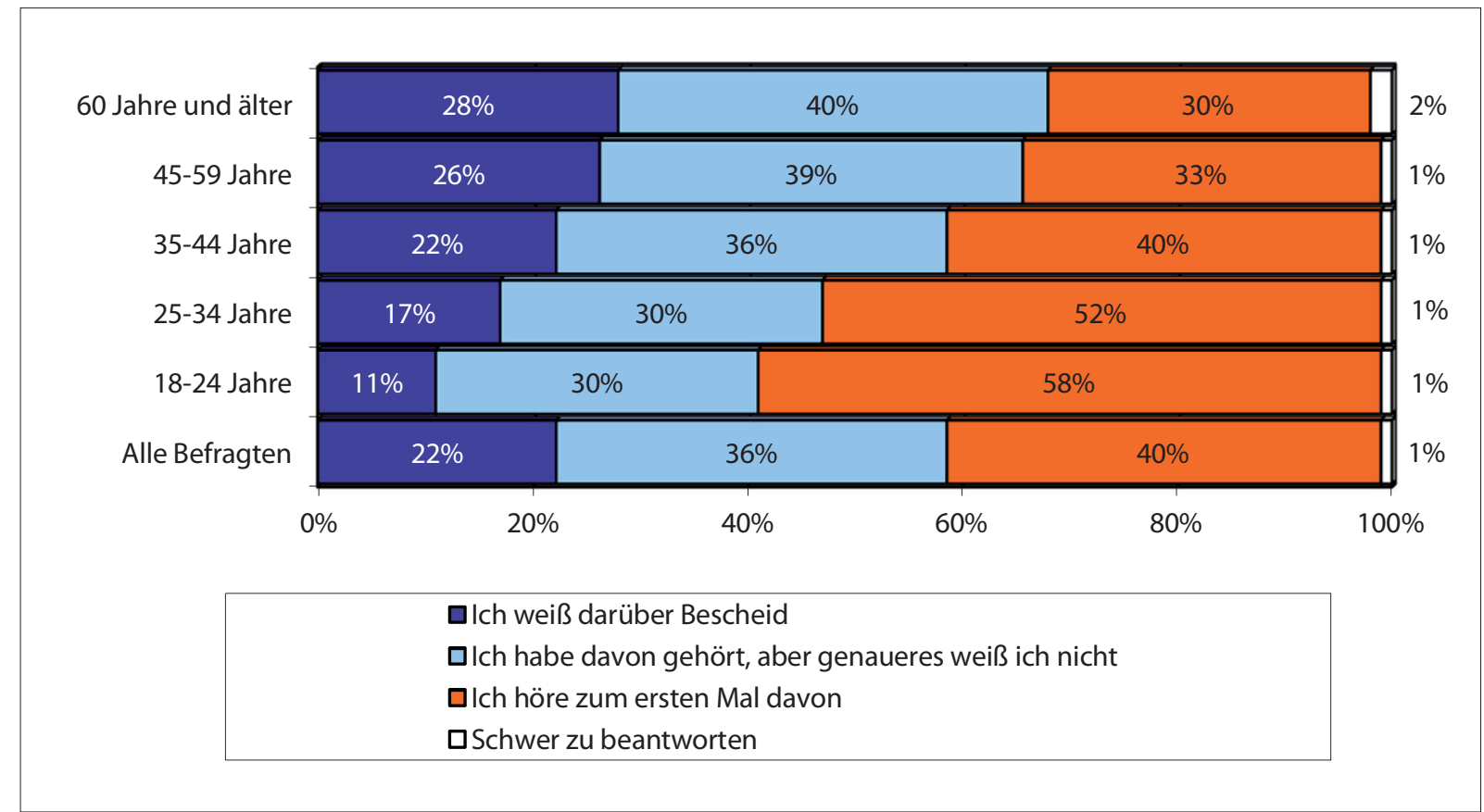

Quelle: Umfrage des WZIOM Meinungsforschungsinstituts vom 4.-5. April 2015, N=1600. Veröffentlicht am 1. Mai 2015 unter: $<$ http://wciom.ru/index.php?id=236\&uid=115233>

\section{AUS RUSSISCHEN BLOGS}

\section{Sexismus-Debatte}

Ende März ist in den unabhängigen Medien und sozialen Netzwerken eine heftige Debatte zum Thema Diskriminierung von Frauen entbrannt. Auslöser dafür war ein misslungener Tweet der unabhängigen Online-Zeitung »Medusa«, der als Beitrag zu einer neuen Serie der FAQ-Karteikarten zum Thema "Sexismus auf Twitter" gedacht war und Männern Anweisungen erteilt, "wie man Tussis nicht beleidigen soll«. Kurz darauf bat ein Großteil der Autoren, die an der Publikation mitgewirkt hatten, ihre Namen aus dem Text zu streichen. Das Thema hat die liberale Öffentlichkeit in zwei Lager gespalten. Die eine Gruppe, unter denen auch einige Menschenrechtler sind, sehen in der Bezeichnung »Tussi« keine Diskriminierung, finden den Tweet lustig und letztlich solch eine ernsthafte Debatte in Zeiten einer zunehmend repressiven Politik Putins und des Krieges in der Ukraine für nicht angemessen. Die andere Gruppe spricht hingegen von einer Verharmlosung von Sexismus, mit welcher Frauen selbst in aufgeklärten Kreisen Tag für Tag konfrontiert sind. Es meldeten sich unter anderem zu Wort der Blogger und Photograph Ilja Warlamow, die Bloggerin Katja Kermlin, die Feministin Bella Rapoport, der Blogger und IT-Experte Anton Nosik und der Journalist Michail Fischman. In der staatlichen Presse fand die Debatte kaum Beachtung.

\section{Ilja Warlamow: Warum unsere Frauen besser sind}

"In letzter Zeit sind die Kämpfer gegen Sexismus aktiver geworden. Ich wollte gerade einen äußerst wichtigen post vorbereiten, warum die Mädels in Russland die schönsten sind. Nun habe ich Angst, ihn zu veröffentlichen. Noch vor einer Woche wäre es ein gewöhnlicher, harmloser Beitrag gewesen. Nun riskiere ich, dass wildgewordene Feminis- 
tinnen mich auf dem Scheiterhaufen verbrennen. Andererseits muss jemand das Weiße weiß nennen, das Schwarze schwarz und die maßlosen Sektierer stoppen.

Die Feministinnen werden mir selbstverständlich Sexismus vorwerfen. Macht nichts, das wäre zum Teil gerecht. Ja, ich finde, dass eine Frau eine Frau sein soll, und ein Mann ein Mann. Und ich schäme mich nicht. Es gibt keine Gender-Gleichheit und es kann auch keine geben, und all eure Versuche, die Geschlechter gleich zu machen sind zum Scheitern verurteilt. Ihr versucht, die Natur zu ändern; das wird euch nicht gelingen. Natürlich könnte es, vielleicht in vielen Generationen, euch tatsächlich gelingen, durch geschlechtliche Selektion die Unterschiede zwischen den Geschlechtern so weit es geht zu verwischen, das wird aber nicht zu unseren Lebzeiten passieren. Und es ist gut, dass ich das nicht sehen werde. [...]

All dieses Gejammer über Diskriminierung der Geschlechter finde ich völlig an den Haaren herbeigezogen. Ja, es gibt stellenweise Diskriminierung, doch die wird durch natürliche Unterschiede der Geschlechter ausgelöst, und nicht durch die Stereotypen der Männer. Ja, ich will, dass meine Assistentin eine junge Frau ist und der Bodyguard (falls ich nach diesem Beitrag einen brauche) ein Mann.

Wenn Sie durch die Länder des siegreichen Feminismus, durch Europa oder die USA reisen, dann haben Sie bestimmt gemerkt, dass dort mit den Frauen etwas nicht in Ordnung ist. Sie sind dort unattraktiv. Woran liegt das? Sie sind durch 50 Jahre [...] Feminismus, der im Westen schon besonders hässliche Formen angenommen hat, dahin gebracht worden,. Als Ergebnis schämt sich die Frau eine Frau zu sein. 'Wenn der Mann haarig ist und stinkt, warum kann ich das nicht auch? Warum darf ich mich nicht anziehen, wie es gerade kommt und im Stehen pinkeln?, denkt die europäische Frau. Sie hören auf, auf sich zu achten, übernehmen männliche Verhaltensformen und verlieren schließlich dadurch ihre Anziehungskraft. Sie scheuen sich, sich wie eine Frau zu kleiden, sie schämen sich für ihre Schwächen, es nervt sie, wenn Männer versuchen, um sie zu werben. In den USA hat das richtig ungesunde Formen angenommen: das sog. 'Sexual Harassment, wenn also jede Handlung des Mannes als Geschlechter-Diskriminierung eingestuft werden kann. Die abgehetzten Männer sind dazu gezwungen, dieses Produkt des Feminismus zu konsumieren und können ihm nicht entgehen.

Zum Glück hält sich unsere Gesellschaft noch. Unsere Frauen schämen sich nicht, Frau zu sein und das ist wunderbar. Sie können schwach und kapriziös sein, man kann im Café für sie bezahlen, ihnen die Tür öffnen, [im Original durchgestrichen: ssie nach Hause schicken, um Borschtsch zu kochen und Kinder zu gebären`. Und niemand wird Dich dafür verurteilen. Deswegen sind unsere Frauen besser. [...]«

Ilja Warlamow auf Livejournal, 25.03.2015 <http://zyalt.livejournal.com/1307622.html>

\section{Katja Kermlin: Russland braucht kaum Feminismus}

»[...] Wenn ich meinen ausländischen Freunden erzähle, wie schlecht es bei uns um die grundlegenden Menschenrechten bestellt ist, füge ich unbedingt hinzu: mit Ausnahme der Frauenrechte. Mit den Frauenrechten ist in Russland alles in Ordnung. Hier heben sich dann die Augenbrauen der Gesprächspartner, sie sperren den Mund auf und stürzen sich auf mich, um mir zu beweisen, dass die Gender-Diskriminierung das größte Problem Russlands sei. Ich lächle [...] und bestehe weiterhin darauf: So sehr braucht Russland den Feminismus nun auch wieder nicht.

Im Westen war das eine völlig andere Geschichte. Bei uns bekamen die Frauen so viele Rechte, wie sie nur mitnehmen konnten. Möchtest du studieren? - Welcome! Arbeiten? - Leg los, meine Liebe, mit jeglicher, schwerster und widerlichster Arbeit. Kämpfen? - Hier ist die MP. Du willst Familienoberhaupt werden, versteht sich, wer sonst könnte das werden. Zieh dich an, wie du möchtest - in den Läden gibt es zwar überhaupt nichts, aber die Länge des Rockes und die Tiefe des Ausschnitts regen niemanden auf. Nein, ich lüge, sie regen die Omas vor deinem Haus auf, die sind aber - trara! - auch keine Männer. Abtreibung? Ach und weh, aber du hast ein Recht darauf.

In einigen der nationalen Republiken ist die Lage nicht so prickelnd, weswegen ich bereit bin anzuerkennen, dass der Kampf für Frauenrechte beispielsweise in Tschetschenien und Dagestan sehr sinnvoll ist. In Saratow aber, ist es dort einer Frau untersagt, ohne Begleitung auf den Markt zu gehen? [...]

Bei uns ist mit den [Frauen]Rechten alles in Ordnung. Es hat im Geschäftsleben nie Gender-Diskriminierung gegeben, von Anfang an, bis die besten westlichen Unternehmenspraktiken zu uns herüberschwappten, mit ihrem diversity, women's clubs, girls get it first. Was ist eigentlich gender diversity? Das ist, wenn der Mann keinen Job kriegt, weil es heißt: 'Sorry, wir haben schon zu viele Männer.

Einmal hat man mir in einem großen internationalen Unternehmen empfohlen, dem Women's club beizutreten, worauf ich antwortete, dass das der abscheulichste Vorschlag ist, der mir je in meiner Karriere untergekommen ist. Die Zuhörer waren schockiert. Ich erklärte, dass ich keine Sonderbedingungen brauche, um den Männern Konkurrenz zu machen. Und dass gerade die Verkündung solcher Bedingungen die kränkendste Diskriminierungsform ist, 
gegen die ich offen kämpfen will. Dass ich in diversen russischen Unternehmen gearbeitet und in einer männlichen Bauarbeiter-Genossenschaft mit äußerst hohem Härtegrad angefangen habe. Und dass ich nirgendwo und noch nie mit einer derart entwürdigenden Unternehmens-Prozedur konfrontiert worden bin, nur weil ich eine Frau bin [...]

Fast hätte ich mein Lieblingswort des letzten Jahres vergessen: Objektivierung. Objektivierung bedeutet, wenn eine Frau Regisseurin, Schriftstellerin, Sängerin, Philosophin, Produzentin oder Medienmanagerin ist, aber ausschließlich als Sexobjekt wahrgenommen wird. Das passiert insbesondere dann, wenn die Frau wie eine Göttin aussieht, ihre Filme aber niemand gesehen hat, ihre Texte scheiße sind, oder sie unter Philosophie prätentiösen Quatsch versteht, den sie aus einigen Büchern zusammengestellt hat. Selbst wenn die Frau eine geniale Neurochirurgin ist, kann sie und hat das volle Recht, sexuelle Wünsche zu wecken.

[...] Lasst uns also nicht schon an einem Punkt beleidigt sein, wo es keinerlei Absicht gab. Unser Geschlecht ist eine aufregende Eigenschaft. Bei dem Versuch, sich zu wehren, sollte man es nicht blindwütig aus der Persönlichkeit rausstreichen. Insbesondere dann nicht, wenn gerade gar keiner angreift."

Katja Kermlin auf Facebook, 10.03.2015 <https://www.facebook.com/photo.php?fbid=1571118536469527>

\section{Bella Rapoport: Der gewöhnliche Sexismus}

"[...] Journalisten, Blogger, SMM-Leute [Social Media Marketing] verstehen wahrscheinlich, dass ihr Leserkreis ungefähr zu gleichen Teilen aus Männern und Frauen besteht. Sie sprechen aber nur die erste Gruppe direkt an und weisen der zweiten die Rolle schweigender Beobachter zu, wenn sie über Frauen in der dritten Person sprechen, vorschlagen, Frauen als Objekt der Betrachtung und Bewunderung wahrzunehmen, negative Stereotype über Frauen verbreiten oder Anreden wie `Muschiki ( (Jungs ) verwenden. Frauen werden selbst oft zum Sprachrohr eines allseits gewohnten und bequemen Ansatzes. So beispielsweise die populäre Bloggerin Katja Kermlin, die sich anscheinend für Menschenrechte einsetzt, und die in einem unheimlich populär gewordenen Beitrag darüber, dass es bei uns um die Menschenrechte schlecht bestellt, mit den Frauenrechten aber alles derart in Ordnung sei, dass man von der Süße der weiblichen Existenz geradezu Diabetes bekommen kann. [...]

Statt die Anstrengungen auf Reflexion und die Entwicklung von Empathie zu richten, versuchen die Anhänger der Wahrung von Menschenrechten und liberalen Werten den Frauen, die etwas als beleidigend empfinden, einzureden, dass sie mit Konstrukten in ihren Köpfen sprechen würden und keinen Sinn für Humor hätten. Vertreter progressiver Medien behandeln Versuche, Sexismus in eine Reihe mit Phänomenen wie Rassismus oder Antisemitismus zu rücken, mit Ironie. Und das in einer Welt, in der nach Angaben der Weltgesundheitsorganisation jede dritte Frau physischer oder sexueller Gewalt ausgesetzt ist. In der Welt, nicht nur in Saudi-Arabien. Überall.

Sexismus erscheint nicht deshalb kein so ernsthaftes Problem zu sein wie andere Diskriminierungsformen, weil es kein ernstes Problem wäre, sondern, weil alle Sphären Bereiche, Schichten und Informationsräume derart von ihm durchdrungen sind, dass alle, einschließlich derjenigen, die unter Sexismus leiden, diesen für die Regel halten. Er wird durch viele, selbst durch die fortschrittlichsten Medien ohne jede Absicht transportiert - und aus reiner Gewohnheit wiedergegeben. Er wird von Angehörigen jener Milieus transportiert, in denen eine ähnliche Rhetorik in Bezug auf andere (wegen ihrer Rasse oder Nationalität) diskriminierte Gruppen als jenseits des Anständigen sowie als marginalen Medien und deren Publikum vorbehalten gilt.

Das Problem verdient eine ernsthaftere und intensivere Diskussion, als ein Gespräch darüber, wer wem in den Mantel hilft. Die fehlende Stimme der Frauen ist zugleich Folge und Grund ihrer Enthumanisierung, die in leichter Form durch Wörtern wie stjolka` [Tussi<; S.M. (bzw. wörtlich ‘weibliches Kalb, Jungkuhı, d. Red.)] und in schwerer Form durch massenhafte Gewalt ihren Ausdruck findet. Wenn anerkannt wird, dass Sexismus Diskriminierung ist, müsste man sich bewusst, aufmerksam und schmerzhaft an seine Ausrottung machen. Es hat jedoch niemand Lust, sich damit zu befassen."

Bella Rapoport auf <colta.ru>, 24.03.2015 <http://www.colta.ru/articles/media/6755>

\section{Anton Nosik: Kreuzzug gegen den Sexismus}

"Die in ihrer Dummheit frappierende feministische Attacke in der gestrigen Colta amüsierte durch die Bekräftigung einer frischen und funkensprühenden Analogie. In einer Frau eine Frau zu sehen, so stellt es sich heraus, das ist das Gleiche wie Antisemitismus. Über eine Frau laut zu sagen, dass du in ihr eine Frau siehst, bedeutet so viel wie Holocaust. [...]

In Wirklichkeit geht es bei dieser Geschichte überhaupt nicht um Gender, Feminismus, weibliche Hysterie und jedes Maß überschreitende politische Korrektheit. Es ist lediglich eine anschauliche Illustration einer Wahrheit, die viele nicht sehen und nicht begreifen wollen. Totalitarismus wird nicht vom Mars auf die Erde geholt und nicht in 
den Laborröhrchen irgendeiner einer beliebigen Fabrik, nennen wir sie mal `Uralwagonsawod`, gezüchtet. Totalitäres Denken steckt in jedem von uns irgendwo im Hinterkopf. Bei jedem Individuum (nicht nur in der Herde) ist ein latentes Bedürfnis vorhanden zu entlarven, zu geißeln, zu brandmarken, ‘die Bösen Tageslicht zu zerren. Als Knüppel taugt hier irgendeine völlig beliebige Ideologie, eine religiöse, politische, nationalistische. Der Feminismus ist für diese Bedürfnisse genau so gut geeignet und ein Instrument für diese Zwecke wie der Islam oder der Eurasismus.

Das Bild wird immer nach dem gleichen Muster gemalt. Es gibt eine Menge von Gerechten (Frauen, Rechtgläubige, wahre Arier/Eurasier). Es gibt eine äußerst mächtige böse Kraft, die sie zu verderben, zertreten, zu erniedrigen und zu beleidigen versucht (Sexisten, Gotteslästerer, Juden/Atlantiker). Proofs werden leicht und locker aufgepumpt: Tolokonnikowa [eine Aktivistin von Pussy Riot] ist Sexistin, die getöteten, französischen Karikaturisten bedrohen die Muslime von Grosnyj, die Rothschilds und Chodorkowskijs sammeln für einen Kreuzzug gegen die Heilige Putinsche Rus vor. Und schon tanzt der Kongress.

Die Sache mit der Kolumne bei Colta ist einfach ein in hohem Maße chemisch reines Laborexperiment: wie aus dem ganz harmlosen Menschenrechtsthema vom Schutz der Frauen vor Alltagsgewalt [...] ein case für diabolische Intoleranz konstruiert wird. Aufgebaut wird er nach denselben Mustern, nach denen Hitler seinerzeit den Genozid an den Sudetendeutschen und 66 Jahre später der Sender `Rossija eine tödliche Bedrohung der Krimtataren durch Schläger des ^Rechten Sektors` erfunden haben. Weil der Mechanismus zur Schaffung von Intoleranz immer gleich ist. Ganz wie die Hirnteile, die solch eine Predigt anregen soll.

Das ist keine Story über Feminismus, Dugin, Hitler, politische Korrektheit oder `Tolerastieı. Das ist eine Geschichte über archaisches Bewusstsein, das unbedingt auf ein `Feindbild ‘ angewiesen ist und eine `Green Card ‘ürs 21. Jahrhundert sucht. Und sie mit einfachen Manipulationen stets findet«.

Anton Nosik auf Livejournal, 25.03.2015; <http://dolboeb.livejournal.com/2791306.html>

\section{Michail Fischman: Medusagate. "Wie der Sexismus in Russland funktioniert"}

»In der Diskussion über Sexismus, die von den Ufern der antisexistischen Karteikarten der `Medusa ausging, gibt es offensichtliche und weniger offensichtliche Dinge. Selbst die offensichtlichen Dinge brechen in auf den ersten Blick erstaunlicher Weise den gewohnten Meinungskonsens unter denjeningen russischen Bürgern auf, die sich für fortschrittlich und modern halten. Die einen beharren darauf, dass über `Tussis` zu twittern grundsätzlich lustig ist. Die anderen, unter denen auch bekannte Feministinnen zu finden sind, stimmen ihnen sogar zu, zumindest in dem Sinne, dass der langwierige Kampf gegen Sexismus aus wichtigeren Schlachten besteht, und dass es sich nicht lohnt, Zeit und Kraft für solch einen Quatsch verschwenden.

Das unmittelbare Gespräch über `Tussis - Darf man oder darf man nicht? Ist es peinlich oder nicht? - ist natürlich an sich wichtig, weil es zeigt, dass es in Bezug auf Sexismus keine festen Regeln gibt und sogar dem fortschrittlichen gesellschaftlichen Bewusstsein nicht ganz klar ist, worum es geht. In Bezug auf Antisemitismus, Rassismus, Homophobie ist es offensichtlich, warum man dagegen kämpfen muss; in Bezug auf Genderdiskriminierung ist aber nicht einmal ganz klar, was das in der Realität bedeutet.

Von `Medusa beispielsweise brauchen Sie keinen Scherz über die Hautfarbe von Barak Obama erwarten. Das ist das Vorrecht von deren Nachfolger bei >lenta.ru< [Viele Mitarbeiter von Medusa hatten früher, bei lenta.ru gearbeitet; d. Red.] (sowie von einiger Abgeordneten, Gouverneuren der annektierter Gebiete und beinahe der gesamten sauflagenstarken Presse). Der Leserschaft von `Medusa ist äußerst wichtig, dass dort keine solchen Scherze zu erwarten sind und 'Medusa weiß darum; das ist ihr sselling point, wie man im Marketing sagt. Eben hierdurch definieren sich sowohl das Medium, als auch seine Leserschaft und der Autor dieser Zeilen unter anderem als aufgeklärter, fortschrittliche Teil der Gesellschaft, der sich dem zunehmenden Fundamentalismus und die allgemeine Barbarei entgegenstellt. Der Kampf gegen Sexismus - und das ist absolut klar - gehört noch immer nicht zur Liste der Qualitätsmerkmale eines anständigen Menschen, weil das Verständnis für diesen Begriff offensichtlich nicht da ist. [...]

Es ist wichtig zu verstehen, dass der Kampf gegen die Genderdiskriminierung keineswegs eine Ansammlung von genau vorgeschriebenen Regeln und von oben herabdiffundierten Wörtern ist, die plötzlich nicht mehr laut gesagt werden dürfen. Es ist ein kompliziertes und bewegliches System sozialer Selbstzensur, das nicht einfach so, um seiner selbst willen existiert, sondern mit einem bestimmten gesellschaftlichen Ziel, nämlich Frauen Sicherheit zu geben, indem gegen Aggression und Gewalt vorgegangen wird. [...]

Politische Korrektheit erwächst aus dem Verständnis, dass es zwischen sexistischen Scherzen, dem `Harassment auf der Straße und der Zahl der Vergewaltigungen und Morde letztlich ein direkter Zusammenhang besteht - ein Zusammenhang, den wir nicht deshalb nicht spüren, weil es ihn in Russland nicht gibt, sondern weil unsere Gesell- 
schaft zerrissen und zudem noch vom Staat unterdrückt ist. Als ob die Männer nicht nebenan trinken und ihre Frauen und Kinder verprügeln, sondern in irgendeiner anderen Realität, die im Wesentlichen aus den (übrigens sehr erschreckenden) Daten von Rosstat [der russischen Behörde für Statistik]; d. Red.] besteht. Wir sind von vornherein überzeugt, dass es leider im Prinzip nicht möglich ist, diesem parallelen Russland zu helfen, und durch das Aufhören mit Witzen über Tussis und Blondinen schon gar nicht. [...]

Das bedeutet aber keineswegs, dass Fortschritt nicht möglich ist. Und umso wichtiger und nützlicher ist die nun endlich erfolgte Diskussion über 'Tussis‘. Politische Korrektheit, die auf erlebten und reflektierten Fällen aufbaut, ist deutlich nachhaltiger und stabiler. Vor kurzem haben wir gesehen, welche Wirkung Präzedenzfälle haben. Hier ein Beispiel: vor zwei Jahren hat der Staat eine homophobe Kampagne unternommen und ist auf eine Reaktion gestoßen. Es gab Debatten, die berühmte Ausgabe von 'Afischar mit den Coming-Outs erschien, was zur Folge hatte, dass sich die Grenzen der Toleranz gegenüber Schwulen in den fortschrittlichen Teilen der Öffentlichkeit merklich geweitet haben, und das dank des Widerstandes als Reaktion auf den unerträglichen homophoben Trend, der von oben angesagt wurde.

Jetzt wird sich etwas Ähnliches wiederholen. Wir werden sehr bald sehen: diejenigen, die Scherze über `Tussis harmlos und einfach nur lustig finden, werden unter unseren Facebook-Freunden weniger werden. Da braucht man nicht einmal mehr neue Karteikarten."

Michail Fischman auf <slon.ru>, 26.03.2015 <https://slon.ru/posts/49724>

\section{Über Gedöns}

Jens Siegert, Moskau

G anz Russland scheint auf dem Weg zurück in finsterste, vormoderne Zeiten. Ganz Russland? Nein, natürlich nicht. Es gibt Hoffnung. Sie mag klein sein, gegenwärtig nicht sehr politikmächtig, aber sie ist da, und manchmal kann man sie sogar sehen. Vor drei Jahren war so ein Moment, als im Winter 2011/2012, wie es schien aus dem Nichts, plötzlich eine Protestbewegung auftauchte, die sogar dem mächtigen Kreml Angst machte. Soviel Angst, dass er, der ideelle Gesamtkreml, zum allumfassenden Gegenschlag ausholte, sich in eine Konfrontation mit dem Westen stürzte, damit das Übel namens »Moderne« mit seinen apokalyptischen Reitern Demokratie, Freiheit und Menschenrechten vor den russischen Toren halt mache.

Nun ist der Winter 2011/2012 lange her, die Krim schon über ein Jahr in russischer Hand und alles Oppositionelle in Russland in tiefer Depression gefangen oder im Exil, oft auch beides. Ins Exil getrieben wurde vor einem Jahr auch ein großer Teil von Russlands bis dato populärster Internetzeitung Lenta.ru. Der Eigner wechselte Mitte März über Nacht Chefredakteurin Galina Timtschenko aus, nachdem die auch für Medien zuständige staatliche Kontrollbehörde "Roskomnadsor" ein Interview mit Andrij Tarasenko, dem Chef des ukrainisch-nationalistischen »Rechten Sektors", als »extremistisch" gerügt hatte. Über 80 Mitarbeiter solidarisierten sich mit Galina Timtschenko und verließen die nun gemainstreamte Redaktion. Nur ein halbes Jahr später, Mitte Oktober 2014, ging, unter Timtschenkos Leitung und mit vielen ehemaligen Lenta-Redakteuren an Bord, »Medusa" online. Sitz der Redaktion ist die lettische Hauptstadt Riga.

Seither versucht die Medusa-Redaktion, erneut zu einem wichtigen Medium auch der Selbstverständigung der liberalen, demokratischen Opposition zu Putin zu werden. Nach überwiegender Meinung, der ich mich anschließe, gelingt das inzwischen immer besser. Soweit der Vorrede. Nun zum eigentlichen Anlass dieser Notizen.

Am 19. März machte die Medusa-Redaktion per Twitter auf einen neuen Artikel mit der Überschrift "Wie kann man in Russland vermeiden, Sexist zu sein?« (<https://meduza.io/cards/kak-ne-byt-seksistomv-rossii >) aufmerksam (das "man« ist hier durchaus als »Mann« zu verstehen). Der Reklame-Tweet lautete: "Männer, hier ist eine Anleitung, wie man Kälbchen nicht beleidigt« (<https://twitter.com/meduzaproject/ status/578564500355416064>). Das von mir hier mit "Kälbchen« übersetze Wort heißt im Russischen »tjolotschki« [siehe auch Anmerkung im Blogbeitrag von Bella Rapoport auf S. 21, d. Red.] und bezeichnet weibliche Kälber, wird aber umgangssprachlich auch, meist von Männern, für Frauen benutzt. Eine deutsche Entsprechung ist nicht so leicht zu finden, aber "Tussi« wohl eine gute Annäherung. Frauen werden dadurch also von 
oben herab und, wenn auch eher freundlich als grob, so doch als sexuelle Objekte betrachtet. Also, hier passt das Wort, natürlich sexistisch.

Dabei will ja der so reklamierte Artikel, wie die Überschrift sagt, das Gegenteil erreichen. Russische Männer sollen sensibilisiert werden, sich eben nicht typisch (also sexistisch) zu verhalten. Dazu werden zehn Fragen gestellt und zehn Antworten gegeben. Es fängt mit Fragen wie "Was ist Sexismus?» an, geht dann aber schnell zu so praktischen wie seltsamen Verhaltenstipps über, wer im Café die Rechnung bezahlen und ob Mann einer Frau die Hand geben soll oder nicht. Kurz: Vielleicht gut gemeint, aber zu kurz gesprungen. Bewusst oder unbewusst werden zahlreiche sexistische Stereotype wiederholt.

Die Reaktion folgte unerbittlich auf dem Fuße. Bella Rapoport, eine junge, aber schon bekannte Feministin, antwortete in der Internetzeitung Colta.ru (die dabei ist, den freigewordenen Platz von Lenta.ru einzunehmen, mit einem Verriss, der nicht nur den Tweet, sondern auch den Medusa-Artikel des "Ganz normalen Sexismus" (<http://www.colta.ru/articles/media/6755>) zeiht. Im Untertitel heißt es: „Wie progressive Medien bewusst oder unbewusst völlig unprogressive Ansichten transportieren «. Medusa, oder zumindest der- oder diejenige, die oder der den Twitter-Account bedient, kann nicht an sich halten und twittert am 24. März zurück: »Männer, schaut mal, unser Tweet hat ein Kälbchen zu einer Kolumne animiert « (<https://twitter.com/ meduzaproject/status/580400313414389760>).

Ob diese wohl als lockerer (und auflockernder) Scherz gemeinte Antwort nun das Fass zum Überlaufen brachte oder schlicht nur zu spät kam, die liberale und demokratische Szene reagierte bereits und es entspann sich die meiner Erinnerung nach hitzigste politische Debatte der vergangenen drei Jahre (wobei der Mord an Boris Nemzow Ende Februar dieses Jahres eine derart besondere Stellung einnimmt, dass sich schon der Gedanke an einen Vergleich verbietet). In schneller Folge äußerten sich alle und alles, was und wer Rang und Namen hat, Blogger, politische Beobachter, Wirtschaftsexperten und einfach nur bekannte Persönlichkeiten. Kein Medium, das etwas auf sich hält, kam an der Debatte vorbei. Dass der Medusa-Tweet etwas angestoßen haben muss, das weitaus mehr Menschen bewegt als die meisten bei diesem Thema gedacht haben, zeigen schon die bis heute (Stand 7. Mai 2015) fast 220.000 Aufrufe von Bella Rapoports Antwortartikel aufColta.ru. Soviel Interesse hat ein feministischer Text in Russland noch nie hervorgerufen.

Die Argumente der »Tjolotschki-Verteidiger« bewegten sich weitgehend in den auch anderswo bekannten Bahnen. Dabei überwogen zwei Argumentationslinien (ich übertreibe der Deutlichkeit wegen bei beiden ein wenig). Die eine stellte der Aufregung um das Wort "tjolotschki« den Ernst der politischen Lage entgegen (insbesondere nach dem Mord an Boris Nemzow): Es gebe momentan Wichtigeres als Etikette und die große (männliche) Politik, der "Kampf gegen das Regime» sollte nicht von solchen Kleinlichkeiten beeinträchtigt werden. Die zweite Argumentationslinie (wenn man sie denn so nennen kann) war unangenehmer, weil abgeschmackt: Diese Feministinnen sollten sich nicht so haben, "tjolotschki« sei doch durchaus nett gemeint. Und überhaupt nehme diese westliche "politische Korrektheit« langsam totalitären Charakter an.

Interessanter Weise sind in dieser Diskussion die üblichen ideologischen Trennlinien kaum zu erkennen. Auch entspann sich der Streit nicht zwischen Männern auf der einen und Frauen auf der anderen Seite. Wenn überhaupt eine Frontlinie sichtbar wurde, dann zieht sie sich meiner Beobachtung nach (und die ist in keiner Weise soziologisch unterfüttert, aber das sind hier ja auch nur Notizen) eher zwischen jung und alt (oder besser: jünger und älter). Vielleicht lässt sich noch eine weitere Unterscheidung machen: möglichst frühe westliche Sozialisation erhöht die Wahrscheinlichkeit, dass jemand »tjolotschki« nicht lässlich findet.

Nun ist es so, dass sich "politisch korrekt« zu verhalten in liberalen und demokratischen Kreisen in Russland längst nicht so out of date ist, wie die Empörung der "Tjolotschki-Verteidiger« zu zeigen scheint. Wenn es, sagen wir, um antisemitische oder rassistische Äußerungen ginge, gäbe es wohl kaum eine Diskussion. Der Grund ist recht einfach: Das "Private» wird in Russland auch im aufgeklärteren Teil der Gesellschaft immer noch kaum als politisch aufgefasst (nicht umsonst flocht Bella Rapoport das Thema »häusliche Gewalt" prominent in ihre Antwort auf den Medusa-Tweet ein).

Man könnte auch (ich weiß, ich betrete hier vermintes Territorium) sagen, Russland hat sein 1968 (noch?) nicht erlebt. Zwar verändern sich auch hier die Herrschaftsverhältnisse zwischen Staat und Individuum ebenso wie zwischen Mann und Frau (oder, um noch weiter zu gehen, Eltern und Kind). Aber die Beschleunigung, die diese Entwicklung im Westen durch das erfahren hat, was heute mit der Zahl "68 « zusammen gefasst wird (auch wenn sich die damals an vorderster Front agierenden Männer sich das sicher so nicht gedacht haben und sich diese Entwicklung selbstverständlich nicht darauf beschränkt), gibt es in Russland nicht.

Es gibt aber auch keinen Stillstand. In den vergangenen, in der russischen Geschichte beispiellos freien 25 Jahren ist eine neue Generation (vielleicht, wenn man anders zählt, auch zwei) herangewachsen, der vor allem eines fehlt: Die (fast) allen sowjetischen Menschen eigene Angst vor der "(Staats)Macht« (die eben auch eine, wie könnte es anderes sein, überwiegend 
männliche Macht ist und sich, nicht zuletzt über die "Schule» Armee, ihre gewalttätigen und frauenverachtenden Männer immer wieder neu zurichtet). Arsenij Roginskij, Vorsitzender von Memorial, hat das vor Jahren in einer Diskussion einmal so ausgedrückt: „Bei jedem von uns sitzt im Kopf ein kleiner Stalin.» Doch nicht nur die Angst fehlt bei diesen eher jüngeren Menschen, es fehlt auch, wenn man so will, der übergroße Respekt vor Autoritäten jeder Couleur. Das zeigt sich bis in den Habitus und ist nicht auf den liberalen Teil der russischen Gesellschaft beschränkt. Diese Entwicklung vollzieht sich in kleinen Schritten, eher im Verborgenen und wird öffentlich, also politisch meist nur in solchen Momenten sichtbar wie dem hier zum Anlass genommenen. Dazu noch drei kleine Beobachtungen.

Die Heinrich Böll Stiftung hatte von 1994 bis 2013 in Russland ein Sur-Place-Stipendienprogramm. Über die Jahre wurden mehr als 350 Student/innen und Doktorend/innen in den Fächern Geschichte, Soziologie und Jura (mit Schwerpunkt Menschenrechte) gefördert. Alljährlich trafen sie sich zu einer Konferenz, die allmählich in eine Sommerschule überging. An diesen Konferenzen/Sommerschulen nahmen auch immer Stipendiat/innen der Heinrich Böll Stiftung aus Deutschland teil. Sie allein schon äußerlich, umso mehr aber in ihrem Verhalten den Organisatoren, Dozenten oder anderen Autoritäten gegenüber, in ihrer Art zu diskutieren und Doziertes in Frage zu stellen (oder eben nicht), von ihren russischen Kolleg/innen zu unterscheiden, war lange kein Problem. Der Unterschied war offensichtlich. Heute sind sie kaum mehr auseinander zu halten.

Nun lässt sich zwar einwenden, unsere Stipendiat/ innen, ausgewählt durch unsere NGO-Partner/innen seien nicht repräsentativ für Russland, sondern nur ein kleiner, zudem sehr "verwestlichter" Ausschnitt. Das stimmt. Ich wage aber trotzdem die Behauptung, dass die Veränderungen, die sich hier zeigen, tief in die gesamte russische Gesellschaft gehen.

Zweite Beobachtung. Die Heinrich Böll Stiftung unterstützt seit Beginn der 1990er Jahre russische NGOs, insbesondere in den Bereichen Ökologie, Geschlechterdemokratie, Menschenrechte und Aufarbeitung der totalitären Geschichte. Seinerzeit verstanden sich NGOs unterschiedlicher inhaltlicher Ausrichtung untereinander oft nicht sonderlich. Interessanter Weise fanden sich unter den Menschenrechtler/innen viele Naturwissenschaftler und Ingenieure, die mit der Anti-Atom-Haltung der Ökologen wenig anfangen konnten. Und beide, Menschenrechtler und Ökologen, nahmen die sich mit Geschlechtergerechtigkeit beschäftigenden Frauen (und es waren fast ausschließlich Frauen) nicht ernst. Das war eine Exotik, die zu tolerieren sie nur bereit waren, weil diese seltsamen, aber netten und hilfreichen Grünen darauf bestanden.
Im Dezember 2001 organisierten wir dann einen ersten Genderworkshop für unsere NGO-Partner/innen, zu dem auch NGO-Vertreter/innen aus Georgien, der Ukraine, Polen, Tschechien und Deutschland eingeladen wurden. Der Workshop hatte zwei Ergebnisse: Die meisten unserer russischen Partner/innen begannen zu verstehen, dass es sich bei Geschlechterfragen nicht schlicht um »Gedöns« handelt (um einen Freund ihres Damals-Schon-Präsidenten zu zitieren) und ihnen wurde klar, wie es ein hier namentlich nicht genannt werden sollender wichtiger NGO-Führer ausdrückte, dass es bei "Gender" nicht nur um Frauen, sondern auch um Männer geht. Diese Entwicklung wäre übrigens ohne den passenden historischen Kontext so wohl nicht passiert. Zur gleichen Zeit wurden sich viele russische NGOs unter dem Druck der einsetzenden Normierungsversuche des nun Putinschen Staates ihrer grundsätzlich gleichgerichteten Interessen eben diesem Staat gegenüber bewusst. Solidarität, selbst wenn sie von außen erzwungen ist, hilft mitunter, (sich) zu verstehen.

Ähnliches wiederholte sich kürzlich, gut zehn Jahre später noch einmal, diesmal schon ohne die pädagogische Einmischung von außen. Die staatliche Repression gegen Schwule und Lesben führte, ebenso über den Umweg Solidarität, zu (zwar nur gewisser, ich gebe es zu, aber doch) Anerkennung. Auch hier lassen sich deutliche Altersunterschiede erkennen.

"Wie weit flog die Tomate?" fragte 1999, 30 Jahre nach dem berühmten Tomatenwurf von Sigrid DammRüger auf dem Frankfurter SDS-Kongress ins ausschließlich männliche Tagungspräsidium, eine Publikation der Heinrich Böll Stiftung. Nicht weit genug, war die erwartbare Antwort der Autorinnen. So ist es selbstverständlich auch in Russland. Das hier Beschriebene ist keine Revolution und wird keine Revolution werden. Es soll aber auf untergründige Änderungen in der russischen Gesellschaft aufmerksam machen, die oft übersehen und von den aktuellen politischen Ereignissen überlagert werden. Diese und ähnliche Änderungen sind die Basis, ja die Voraussetzungen, dass es beim nächsten Versuch, ein demokratischeres, menschlicheres Russland aufzubauen, vielleicht ein wenig besser klappt.

Die Medusa-Twitter-Geschichte endete übrigens mit einer Entschuldigung: "Der Tweet (ihr wisst schon, welcher) war grob, wir bitten bei allen um Entschuldigung, die wir beleidigt haben. Wir behalten ihn als Fehler im Gedächtnis. Wir wollten nichts Böses und lieben alle.« (<https://twitter.com/meduzaproject/ status/580742267239006208>).

Diesen und andere Texte finden Sie aufJens Siegerts Russlandblog <http://russland.boellblog.org/>. 


\section{April - 7. Mai 2015}

23.4.2015 Entgegen einer früheren Ankündigung plant die oppositionelle Zeitung »Nowaja Gaseta«, ihre Printausgabe nun doch beizubehalten. Derzeit werden Gespräche mit mehreren potenziellen Investoren geführt. Die zwei Mal wöchentlich erscheinende Zeitung hatte aufgrund fehlender Finanzierung erwogen, die Produktion im Mai einzustellen und lediglich die Online-Sparte beizubehalten.

23.4.2015 Auf finnische Initiative hin führt Präsident Wladimir Putin ein Telefongespräch mit dem finnischen Präsidenten Sauli Niniistö. Themen sind die russisch-finnische Zusammenarbeit, u. a. im Kontext der Beziehungen zwischen Russland und der EU sowie mit Blick auf Kooperationen in der Arktis. Es wird auch über Maßnahmen zur Umsetzung des Minsker Abkommens gesprochen.

23.4.2015 Präsident Wladimir Putin empfängt die argentinische Präsidentin Cristina Fernandez de Kirchner in Moskau. Bei dem Treffen werden eine Reihe von Vereinbarungen unterzeichnet, u. a. zur wirtschaftlichen Entwicklung sowie zur militärischen und kulturellen Zusammenarbeit zwischen den beiden Ländern. Außerdem wird beschlossen eine umfassende russisch-argentinische strategische Partnerschaft aufzubauen.

23.4.2015 Die Generalstaatsanwaltschaft entschuldigt sich offiziell bei der wegen Spionage beschuldigten Swetlana Dawydowa. Nach Angaben des Anwalts von Dawydowa ist seine Mandantin vom Straftatbestand des Staatsverrats in allen Punkten freigesprochen worden. Dawydowa hatte 2014 wiederholt die ukrainische Botschaft über Truppenbewegungen an der Grenze informiert und war daraufhin beschuldigt worden Spionage zugunsten der Ukraine betrieben zu haben.

24.4.2015 Das regierungsnahe »Institut für Gesetzgebung und Vergleichende Rechtslehre" (IZISP) stellt einen neuen Korruptions-Monitoring-Index vor. Der Index solle den Experten zufolge weniger subjektiv sein als vergleichbare Indizes, da er mit einem breiteren System von Indikatoren arbeite. Er soll eine Alternative zu etablierten Ratings (etwa den Indizes von Transparency International oder der Weltbank) darstellen. Der Index wird derzeit in Russland und Kirgistan getestet.

24.4.2015 Präsident Wladimir Putin besucht die armenische Hauptstadt Jerewan. Er nimmt dort an den Gedenkfeierlichkeiten zum 100. Jahrestag des Völkermords an den Armeniern teil. Putin trifft auch den armenischen Präsidenten Sersch Sargsjan zu Gesprächen. Es geht um vertiefte Zusammenarbeit im Bereich der Integration beider Länder in diversen Staatengemeinschaften. Des Weiteren trifft Putin in Jerewan auf den französischen Präsidenten François Hollande, mit dem er über eine Verbesserung der russisch-französischen Beziehungen spricht.

24.4.2015 Im Rahmen einer Antiterror-Operation im Rayon Karabudachkent (Republik Dagestan) werden drei Menschen getötet. Ein Mann wird während einer Schießerei mit den Einsatzkräften getötet, während zwei weitere Kämpfer einer unbekannten terroristischen Organisation später in einem Bunker unter dem Haus, in dem die Operation stattfand, gefunden werden. Es werden größere Mengen Waffen und Munition beschlagnahmt.

24.4.2015 Anlässlich der Feierlichkeiten zum 70. Jahrestag des Sieges über Nazi-Deutschland, wird eine Amnestie-Verordnung des Präsidenten von der Staatsduma verabschiedet. Die Amnestie betrifft etwa 60.000 in Gefängnishaft befindliche sowie rund 200.000 auf Bewährung verurteilte Personen. Der Oppositionsabgeordnete Dmitrij Gudkow hatte zuvor über Twitter mitgeteilt, dass alle seine Änderungsanträge zum Amnestieprojekt abgelehnt worden waren. Er hatte sich u. a. für eine Freilassung der im »Bolotnaja-Verfahren« Verurteilten eingesetzt.

24.4.2015 Der Europäische Gerichtshof für Menschenrechte (EGMR) erklärt den Arrest von Aleksej Nawalnyj und Ilja Jaschin im Dezember 2011 für nicht rechtmäßig. Dem Gericht zufolge steht beiden Männern jeweils 26.000 Euro Entschädigung zu.

24.4.2015 Nach Angaben der Straftermittlungsbehörde der Republik Tschetschenien kommt einer der Verdächtigen im Mordfall Nemzow, Beslan Schawanow, während eines Festnahmeversuchs durch Beamte aus Moskau ums Leben. Er soll sich in Grosnyj in seiner Wohnung selbst in die Luft gesprengt haben. Der ehemalige Kämpfer im Bataillon "Nord» soll ein Komplize des Beschuldigten Saur Dadajew gewesen sein.

25.4.2015 Nach Angaben des Verteidigungsministeriums wird bis 2018 eine Umgehungsstrecke der Verbindung ShurawkaTschertkowo, die bislang direkt durch die Ukraine führte, gebaut werden. Das Bauprojekt wird von russischen Eisenbahntruppen durchgeführt und soll 55 Mio. Rubel (fast 1 Mio Euro) kosten.

25.4.2015 In der dagestanischen Hauptstadt Machatschkala werden während einer Antiterror-Operation unter der Leitung des Nationalen Antiterror-Komitees zwei Kämpfer getötet, die zur Terrormiliz »Islamischer Staat" gehört haben sollen.

25.4.2015 Die Oppositionspartei "Jabloko« erklärt, dass sie den Parteigründer Grigorij Jawlinskij als Präsidentschaftskandidat für die Wahlen 2018 aufstellen will.

25.4.2015 Der russische Biker-Club «Nachtwölfe« bricht zu einer Moskau-Berlin-Tour zum Gedenken an den 70. Jahrestag des Sieges über Nazi-Deutschland auf. An der polnischen Grenze wird ihnen die Weiterfahrt untersagt. Die russische Regierung fordert eine Erklärung. 
25.4.2015 Von einer Gruppe von Mädchen, die im Twerking-Stil vor dem vaterländischen Kriegsdenkmal »Malaja Semlja« in Noworossijsk tanzten und das Video in sozialen Netzwerken einstellten, werden drei zu 10-15 Tagen Arrest verurteilt. Weitere Mädchen werden mit Geldstrafen belegt. Auch den Eltern zweier Mädchen droht eine Klage.

26.4.2015 Auf dem Staatskanal Rossija-1 wird ein Dokumentarfilm über Wladimir Putin gezeigt. In dem Film mit dem Titel "Der Präsident« verurteilt Putin unter anderem den Einsatz von Terroristen durch Staaten zum Zwecke der Erreichung von kurzfristigen politischen oder geopolitischen Zielen. Putin deutet in dem Film an, dass amerikanische Geheimdienste Anfang der 2000er Jahre in engem Kontakt mit tschetschenischen Separatisten gestanden hätten.

27.4.2015 Nach Angaben des russischen Verteidigungsministeriums führt eine Gruppe von norwegischen und amerikanischen Inspektoren drei Tage lang Beobachtungsflüge über russischem Territorium durch. Die Flüge finden im Rahmen des Vertrages über den Offenen Himmel statt und werden von russischen Spezialisten an Bord begleitet.

27.4.2015 Präsident Wladimir Putin gratuliert in einem Telefonat dem kasachischen Präsidenten Nursultan Nasarbajew zum Wahlsieg. Desweiteren erörtern die Präsidenten Fragen zum Ausbau der strategischen Partnerschaft zwischen beiden Ländern.

28.4.2015 Das russische Justizministerium entzieht der Fortschrittspartei von Aleksej Nawalnyj die Registrierung. Der Partei war es nicht gelungen innerhalb von sechs Monaten in mindestens 44 Regionen regionale Filialen zu gründen. Vertreter der Partei kündigen an, beim Europäischen Gerichtshof für Menschenrechte Beschwerde einzureichen.

28.- $\quad$ Der unbemannte russische Weltraumtransporter »Progress M-27 M" verfehlt nach dem Start vom Weltraumbahn-

29.4.2015 hof Bajkonur (Kasachstan) auf dem Weg zur internationalen Raumstation ISS aus bisher nicht geklärten Gründen die vorgesehene Umlaufbahn und gerät außer Kontrolle der Flugleitzentrale (ZUP).

29.4.2015 Mehr als 5.000 der 30.000 Arbeiter des Unternehmens »Uralwagonsawod« (UWS, Nishnij Tagil) sind bis Ende Mai bei 2/3 Lohnfortzahlung in den Zwangsurlaub geschickt worden. Gründe seien die schlechte Auftragslage und die Stagnation am Markt.

29.4.2015 Das russische Justizministerium registriert die NGOs »Perm-36 « sowie die »Frauenliga» (Kaliningrad) als »ausländische Agenten«. Das Register umfasst nun 58 Organisationen.

29.4.2015 Nach Angaben der föderalen Agentur für Bildungsaufsicht (Rosobrnadsor) wurden im laufenden Jahr 2015 insgesamt 103 Hochschulen oder deren Außenstellen die Akkreditierung entzogen.

29.4.2015 Nach Angaben des Generalstaatsanwalts Jurij Tschajka werden wegen diverser Verstöße im Zusammenhang mit dem Bau des Kosmodroms »Wostotschnyj« 20 Strafverfahren eröffnet. In den letzten Monaten waren wiederholt Arbeiter wegen ausbleibender Lohnzahlungen in den Hungerstreik getreten. Die Chefs der betroffenen Subunternehmen wurden wegen des Verdachts auf Hinterziehung von Lohngeldern bereits festgenommen.

30.4.2015 Im Rahmen des Föderalen Zielprogramms »Sozio-ökonomische Entwicklung der Kurilen-Inseln im Zeitraum 20162025 « werden nach Angaben des Ministeriums für die Entwicklung des Fernen Ostens 68,9 Milliarden Rubel (ca. 1,2 Milliarden Euro) zur Verfügung gestellt.

30.4.2015 Präsident Wladimir Putin führt ein Telefongespräch mit Bundeskanzlerin Angela Merkel sowie den Präsidenten François Hollande und Petro Poroschenko. Im Normandie-Format werden weitere Möglichkeiten zur Konfliktlösung in der Ukraine diskutiert, insbesondere die Etablierung von Unterarbeitsgruppen der Kontaktgruppe, mithilfe derer der notwendige Dialog zwischen der Kiewer Regierung und den Vertretern des Donbass durchgeführt werden soll.

1.5.2015 In Nowosibirsk findet ein nicht genehmigter Demonstrationszug von Jugendlichen statt. Das Motto des jährlichen karnevalsähnlichen Umzugs lautet 2015: „Genug der Demütigung«. Die ca. 2.000 Teilnehmer werden von der Polizei daran gehindert. sich an den städtischen 1. Mai-Umzug anzuschließen. Der Organisator wird festgenommen und wenige Tage später zu zehn Tagen Arrest und einer Geldstrafe verurteilt.

1.5.2015 In Moskau nehmen über 100.000 Menschen an dem traditionellen 1. Mai-Umzug teil. Das Motto des Umzugs lautet 2015 »Preisanstieg - Verdopplung der Gehälter!«. Die Veranstaltung wird neben den Gewerkschaften auch von der Partei "Einiges Russland« sowie der "Allrussischen Volksfront« unterstützt.

1.5.2015 Im russischen sozialen Netzwerk »VKontakte« erscheint eine Seite des Oberhaupts der Russischen Orthodoxen Kirche, Patriarch Kirill. Der Patriarch hatte in der Vergangenheit wiederholt betont, dass Präsenz christlicher Bezeugungen in den sozialen Netzwerken wichtig sei.

2.5.2015 Präsident Putin unterzeichnet ein Gesetz zur Ratifizierung des Vertrags über die Gründung eines Fonds für Devisenreserven der Staatengemeinschaft BRICS. Der Umfang des Fonds beträgt 100 Milliarden US-Dollar. Die BRICSStaaten beabsichtigen sich mit der Einrichtung des Fonds künftig besser vor Devisen- und Finanzmarktturbulenzen zu schützen. Russlands Beitrag beträgt 18 Milliarden US \$.

2.5.2015 Die russische Primaballerina Maja Plisezkaja stirbt im Alter von 89 Jahren an Herzversagen in München. Plisezkaja hatte zwischen 1943 und 1989 am Bolschoi-Theater getanzt und Weltruhm erlangt. Später machte sie sich auch als Choreografin einen Namen. 


\begin{tabular}{|c|c|}
\hline 3.5 .2015 & $\begin{array}{l}\text { Zwischen der NATO und der russischen Militärführung wird auf Initiative des deutschen Außenministers Frank- } \\
\text { Walter Steinmeier der sogenannte »direkte Draht« für Krisensituationen wieder ins Leben gerufen. Die direkte Ver- } \\
\text { bindung zwischen den Militärs, die infolge der Kuba-Krise } 1962 \text { zwischen Washington und Moskau eingerichtet } \\
\text { wurde, war nach Beginn der Ukraine-Krise unterbrochen worden. }\end{array}$ \\
\hline 4.5 .2015 & $\begin{array}{l}\text { Präsident Putin unterzeichnet ein Gesetz, das das bestehende Übereinkommen zwischen Russland und Belarus über } \\
\text { den grenzüberschreitenden Gütertransit zwischen Zollbehörden aufhebt. Vorangegangen war die Wiedereinführung } \\
\text { von Zollkontrollen auf der belorussischen Seite in Reaktion auf verstärkte phytosanitäre Kontrollen von landwirt- } \\
\text { schaftlichen Produkten aus Weißrussland auf russischer Seite. }\end{array}$ \\
\hline 5.5.2015 & $\begin{array}{l}\text { Das russische Verteidigungsministerium aktiviert das Internet-Portal "Gedenken des Volkes«, eine Datenbank über } \\
\text { das Schicksal von Kriegshelden. Die Bürger sollen nun über die Heldentaten ihrer Vorfahren erfahren können, die } \\
\text { im 1. oder 2. Weltkrieg gefallen sind. }\end{array}$ \\
\hline 5.5.2015 & $\begin{array}{l}\text { Der russische Verteidigungsminister Sergej Schojgu gibt bekannt, dass die russischen Streitkräfte während des Win- } \\
\text { ter-Halbjahres (Anfang Dezember bis Ende April) insgesamt } 886 \text { Militärübungen auf unterschiedlichen Ebenen zu } \\
\text { Lande, zu Wasser und in der Luft durchgeführt haben. }\end{array}$ \\
\hline 5.5.2015 & $\begin{array}{l}\text { Nachdem Präsident Putin sich telefonisch mit dem israelischen Premier-Minister Benjamin Netanjahu in Verbindung } \\
\text { gesetzt hat, nimmt die israelische Regierung Abstand von einem Rüstungsdeal der Firma IAI mit der Ukraine. Geplant } \\
\text { war der Verkauf von Militärdrohnen an die Ukraine zur Überwachung des Waffenstillstands in der Ostukraine. }\end{array}$ \\
\hline 5.5.2015 & $\begin{array}{l}\text { Bei der Generalprobe am Vorabend der Premiere des Theaterstücks »Bolotnaja-Sache« im unabhängigen Moskauer } \\
\text { "Theater.doc« nehmen Vertreter der russischen Rechtschutzorgane teil. Die Premiere des Dokumentarstücks »Bolot- } \\
\text { naja-Sache« findet am dritten Jahrestag der Proteste auf dem Bolotnaja Platz in Moskau statt. }\end{array}$ \\
\hline 6.5 .2015 & $\begin{array}{l}\text { Ein Moskauer Gericht verurteilt Jewgenija Wasiljewa, eine ehemalige Beschäftigte des russischen Verteidigungs- } \\
\text { ministeriums, zu einer mehrjährigen Haftstrafe. Vier weitere Personen werden schuldig gesprochen. Wasiljewa war } \\
\text { beschuldigt worden, bei Immobiliengeschäften mit dem Verteidigungsdienstleister »Oboronserwis« } 3 \text { Milliarden } \\
\text { Rubel (ca. } 52 \text { Millionen Euro) hinterzogen zu haben. Der Korruptionsskandal hatte } 2012 \text { zur Entlassung des dama- } \\
\text { ligen Verteidigungsministers Serdjukow geführt. }\end{array}$ \\
\hline 6.5 .2015 & $\begin{array}{l}\text { Nach Angaben des russischen Finanzministeriums sind der russische Reservefonds und der Fonds für nationale } \\
\text { Wohlfahrt im April um 10, } 7 \% \text { bzw. 9,2\% geschrumpft. Noch am 1. April } 2015 \text { hatte der Reservefonds rund 4,5 } \\
\text { Trillionen Rubel (ca. 75,7 Milliarden USD) umfasst. }\end{array}$ \\
\hline 6.5 .2015 & $\begin{array}{l}\text { In der Moskauer Innenstadt finden mehrere nicht genehmigte Kundgebungen zum Jahrestag der Proteste auf dem } \\
\text { Bolotnaja-Platz im Mai } 2012 \text { statt, bei denen die Freilassung der "politischen Häftlinge« des »Bolotnaja-Verfahrens" } \\
\text { gefordert wird. } 46 \text { Personen werden festgenommen. }\end{array}$ \\
\hline 7.5 .2015 & $\begin{array}{l}\text { Nach Angaben des russischen Ministerkabinetts wurden die Mai-Erlasse des Präsidenten seit } 2012 \text { zu 81,5\% umge- } \\
\text { setzt. Diese Vorgaben betreffen zumeist akute soziale Probleme in Russland wie das Gesundheitswesen und die Ren- } \\
\text { ten- und Familienpolitik. Bis Ende } 2015 \text { muss die Regierung hierüber Rechenschaft ablegen. }\end{array}$ \\
\hline
\end{tabular}

Sie können die gesamte Chronik seit 1964 auch auf <http://www.laender-analysen.de/russland/> unter dem Link "Chronik" lesen.

Die Russland-Analysen werden von Mangold Consulting GmbH unterstützt.

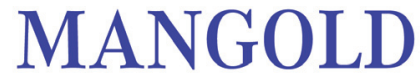

$\mathrm{C}$ o $\mathrm{n}$ s u l $\mathrm{t}$ i $\mathrm{n} \mathrm{g}$

Herausgeber: Forschungsstelle Osteuropa an der Universität Bremen und Deutsche Gesellschaft für Osteuropakunde

Die Meinungen, die in den Russland-Analysen geäußert werden, geben ausschließlich die Auffassung der Autoren wieder. Abdruck und sonstige publizistische Nutzung sind nach Rücksprache mit der Redaktion gestattet. Redaktion: Hans-Henning Schröder (verantwortlich), Nadja Douglas Sprachredaktion: Hartmut Schröder Satz: Matthias Neumann

Russland-Analysen-Layout: Cengiz Kibaroglu, Matthias Neumann und Michael Clemens Alle Ausgaben der Russland-Analysen sind mit Themen- und Autorenindex archiviert unter www.laender-analysen.de Die Russland-Analysen werden im Rahmen eines Lizenzvertrages in das Internetangebot der Bundeszentrale für politische Bildung (www.bpb.de) aufgenommen. Die Russland-Analysen werden im Rahmen der Datenbank World Affairs Online (WAO) ausgewertet und sind im Portal IREON www.ireon-portal.de recherchierbar. ISSN 1613-3390 @ 2015 by Forschungsstelle Osteuropa, Bremen

Forschungsstelle Osteuropa • Publikationsreferat • Klagenfurter Str. 3 • 28359 Bremen • Telefon: +49 421-218-69600 • Telefax: +49 421-218-69607 e-mail: publikationsreferat@osteuropa.uni-bremen.de•Internet-Adresse: http://www.laender-analysen.de/russland/ 


\section{Kostenlose E-Mail-Dienste der Forschungsstelle Osteuropa und ihrer $\square$ Partner auf www.laender-analysen.de}

Die Länder-Analysen bieten regelmäßig kompetente Einschätzungen aktueller politischer, wirtschaftlicher, sozialer und kultureller Entwicklungen in Ostmitteleuropa und der GUS. Sie machen das Wissen, über das die wissenschaftliche Forschung in reichem Maße verfügt, für Politik, Wirtschaft, Medien und die interessierte Öffentlichkeit verfügbar. Autoren sind internationale Fachwissenschaftler und Experten.

Die einzelnen Länder-Analysen werden von der Forschungsstelle Osteuropa an der Universität Bremen und der Deutschen Gesellschaft für Osteuropakunde jeweils mit unterschiedlichen Partnern und Sponsoren herausgegeben.

Die Länder-Analysen bieten regelmäßig Kurzanalysen zu aktuellen Themen, ergänzt um Grafiken und Tabellen sowie Dokumentationen. Zusätzlich gibt es eine Chronik aktueller Ereignisse.

\section{Belarus-Analysen}

Erscheinungsweise: zweimonatlich

Abonnement unter: <http://www.laender-analysen.de/belarus/>

\section{Caucasus Analytical Digest}

In englischer Sprache. Erscheinungsweise: monatlich

Abonnement unter: $<$ http://www.css.ethz.ch/publications/newsletter_CAD_EN>

\section{Polen-Analysen}

Erscheinungsweise: zweimal monatlich

Abonnement unter: <http://www.deutsches-polen-institut.de/Newsletter/subscribe.php >

\section{Russland-Analysen}

Erscheinungsweise: zweiwöchentlich

Abonnement unter: <http://www.laender-analysen.de/russland/>

\section{Russian Analytical Digest}

In englischer Sprache. Erscheinungsweise: zweimal monatlich Abonnement unter: $<$ http://www.css.ethz.ch/publications/newsletter_RAD_EN>

\section{Ukraine-Analysen}

Erscheinungsweise: zweimal monatlich

Abonnement unter: <http://www.laender-analysen.de/ukraine/>

\section{Zentralasien-Analysen}

Erscheinungsweise: monatlich

Abonnement unter: <zentralasien-analysen@dgo-online.org>

\section{Bibliographische Dienste}

Die Bibliographien informieren über englisch- und deutschsprachige Neuerscheinungen zu Belarus, Russland, Ukraine sowie zu den zentralasiatischen und kaukasischen Staaten. Erfasst werden jeweils die Themenbereiche Politik, Außenpolitik, Wirtschaft und Soziales.

Erscheinungsweise: viermal jährlich

Abonnement unter: Belarus: <http://www.laender-analysen.de/bibliographies/belarus.php>; Russland: <http://www. laender-analysen.de/bibliographies/russia.php>; Ukraine: <http://www.laender-analysen.de/bibliographies/ukraine. php>; zentalasiatische und kaukasische Staaten: <http://www.laender-analysen.de/bibliographies/caucasus_ca.php>

\section{Twitter}

$<$ https://twitter.com/laenderanalysen $>$ 